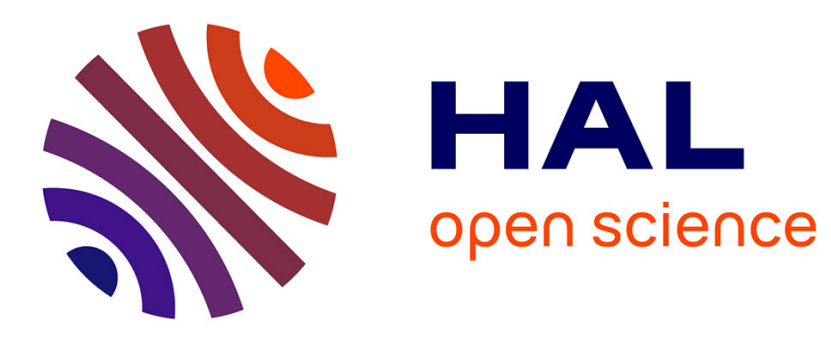

\title{
Groupe de recherches sur les missions ibériques modernes, Politiques missionnaires sous le pontificat de Paul IV. Un document interne de la Compagnie de Jésus en 1558
}

Pierre Antoine Fabre

\section{To cite this version:}

Pierre Antoine Fabre. Groupe de recherches sur les missions ibériques modernes, Politiques missionnaires sous le pontificat de Paul IV. Un document interne de la Compagnie de Jésus en 1558. Mélanges de l'École française de Rome - Italie et Méditerranée, 1999, 111 (1), pp.277 - 344. 10.3406/mefr.1999.4618 . hal-01791659

\author{
HAL Id: hal-01791659 \\ https://hal.science/hal-01791659
}

Submitted on 14 May 2018

HAL is a multi-disciplinary open access archive for the deposit and dissemination of scientific research documents, whether they are published or not. The documents may come from teaching and research institutions in France or abroad, or from public or private research centers.
L'archive ouverte pluridisciplinaire HAL, est destinée au dépôt et à la diffusion de documents scientifiques de niveau recherche, publiés ou non, émanant des établissements d'enseignement et de recherche français ou étrangers, des laboratoires publics ou privés. 


\section{Groupe de recherches sur les missions ibériques modernes, Politiques missionnaires sous le pontificat de Paul IV. Un document interne de la Compagnie de Jésus en 1558}

\section{Résumé}

Groupe de recherches sur les missions religieuses ibériques modernes, Politiques missionnaires sous le pontificat de Paul IV. Un document interne de la Compagnie de Jésus en 1558, p. 277-344.

Cet article est le fruit d'une enquête collective sur un document peu connu (publié en annexe) produit par l'administration centrale de la Compagnie de Jésus en 1558, concernant l'ensemble des questions liées au développement de l'entreprise missionnaire de l'Ordre dans les Indes orientales et occidentales et en Afrique. L'analyse intervient sur trois plans de réalité différents, celui de l'insertion sociale et économique de l'institution jésuite dans le monde colonial, celui des relations de cette institution avec les clergés locaux, celui enfin du fonctionnement interne de l'ordre missionnaire, avec le projet d'évaluer la spécificité de la « mission religieuse » dans le contexte de l'expansion européenne, en situant toujours l'interprétation de ce texte elliptique, mais global et pénétrant, par rapport à deux exigences contemporaines du nouvel Ordre : celle d'imposer une marque identifiable, pour l'extérieur mais aussi pour lui-même, sur des terrains extrêmement divers, celle de faire reconnaître cette marque à Rome, dans une période de réflexion intense sur le destin du catholicisme dans le monde et les instruments de ce destin.

\section{Citer ce document / Cite this document :}

Groupe de recherches sur les missions ibériques modernes, Politiques missionnaires sous le pontificat de Paul IV. Un document interne de la Compagnie de Jésus en 1558. In: Mélanges de l'Ecole française de Rome. Italie et Méditerranée, tome 111, n¹. 1999. pp. 277-344;

doi : https://doi.org/10.3406/mefr.1999.4618

https://www.persee.fr/doc/mefr_1123-9891_1999_num_111_1_4618

Fichier pdf généré le 05/04/2018 


\title{
POLITIQUES MISSIONNAIRES SOUS LE PONTIFICAT DE PAUL IV
}

\author{
UN DOCUMENT INTERNE \\ DE LA COMPAGNIE DE JÉSUS EN $1558^{2}$
}

Nous nous sommes proposés l'étude d'un mémoire ${ }^{3}$ de quelques pages, rédigé à Rome en 1558, qui dresse une sorte d'état des lieux des missions jésuites hors d'Europe dans cette période. Pourquoi cette année - 1558 nous a-t-elle semblé une date "sensible»? D'une part, nous étions attentifs à la situation de la Compagnie de Jésus (deux ans après la mort de son fondateur, Ignace de Loyola) dans le contexte romain de la fin des années 1550, sous le pontificat de Paul IV, dans une phase de stabilisation de la Contre-Réforme catholique "à l'intéricur", et d'élaboration d'une politique ecclésiastique globale "à l'extérieur», dans le monde non-chrétien, paral-

'Groupe de recherches sur les missions religieuses ibériques modernes, École des hautes études en sciences sociales - École française de Rome : Charlotte de Castelnau (C. d. C.), Pierre Antoine Fabre (P. A. F.), Pascale Girard (P. G.), Jean-Claude Laboric (J.-C. L.), Aliocha Maldavsky (A. M.), Bernard Vincent (B. V.), Carlos Zerón (C. Z.), Jean-Paul Zuñiga (J.-P. Z.) et Ines G. Zupanov (I. G. Z.).

${ }^{2}$ L'analyse du document de 1558 a fait l'objet d'une élaboration collégiale, chacun des membres du Groupe de recherches restant cependant librement responsable de sa contribution personnelle, dans un ensemble auquel nous avons souhaité conserver son mode "polyphonique".

${ }^{3}$ On trouvera en annexe la traduction française de ce texte, réalisée dans le cadre de l'enquête. L'original latin du document, conservé dans les Archives romaines de la Compagnie de Jésus, a été publié une première fois par Pedro Leturia en 1939 dans la revue Archivum historicum Societatis lesu [désormais AHSI] (P. Leturia, Un significativo documento de 1558 sobre las misiones de infieles de la Compania de Jesús, dans AHSI, 8, 1939, p. 102-117), puis par J. Wicki en 1956, dans DI, IV, p. 72-80 (bien que le document concerne l'ensemble des terres de mission, et non pas seulement l'Inde, qui avait cependant été la première destination des jésuites hors d'Europe, à l'époque de François Xavier : mais l'inscription du texte de 1558 dans les $D I$ n'est pas chronologiquement rigoureuse, et réaffirme plutôt une certaine hiérarchie des terres de mission et la préćminence du modèle indien). 
lèlement et concurrement à l'établissement du "padroado", gouvernement impérial des affaires religieuses dans les territoires d'outre-mer. Or ces deux traits du pontificat de Paul IV sont aussi deux menaces pour la Compagnie de Jésus : l'avant-garde de la Contre-Réforme des années 1540 court le risque d'être "digérée" dans le recentrage romain (c'est autour de 1558 que certains grands prélats réformateurs - comme par exemple Giovanni Morone, évêque de Modène, auquel s'était violemment affronté Alonso Salmerón, l'un des premiers compagnons d'Ignace de Loyola, au début des années 1540 - reviennent aux affaires à Rome); les initiatives romaines à l'extérieur peuvent réduire l'avance et la marge de manœuvre des missions jésuites, massivement et intensivement lancées dès le début des années 1540.

Deux faits marqueront, dix ans après la rédaction de notre texte, l'affleurement de ce qui est d'ores et déjà souterrainement en jeu. En 1568, le général François de Borgia produit une instruction sur les missions qui reste le premier document officiel global sur le sujet et, parallèlement, intervient fortement entre 1566 et 1572, principalement par le biais d'une médiation entre l'église romaine, l'Espagne et le Portugal, dans le projet d'une congrégation "pour la conversion des infidèles», projet auquel Philippe II fera finalement obstacle, mais qui peut être considéré comme une étape importante sur la voie de la création de la congrégation De propaganda fide, en $1622^{4}$.

La question des missions est assurément l'une de celles, en 1558, sur lesquelles la Compagnie de Jésus peut occuper le terrain "romain». Un seul exemple : le problème de la datation exacte de notre texte. L'un des arguments apportés par Pedro Leturia, lorsqu'il publie ce document en 1939, pour situer le texte avant la mi-février 1558 est que le 18 février, Laínez, vicaire de l'ordre depuis la mort d'Ignace de Loyola (et futur général, après la congrégation générale de mai-juillet 1558), obtient de Paul IV, avec lequel les relations du nouvel institut n'avaient pas été faciles ${ }^{5}$ une série de $\mathrm{fa}$ cultates ou dispenses exceptionnelles pour la Compagnie dans les terres de mission, dont notre document formule le souhait ( $§ 4)$. Mais cela nous dit

${ }^{4}$ Voir sur ces points P. Leturia, Felipe II y el pontificado en un momento culminante de la historia hispano-americana, dans Estudios ecclesiásticos, 5, 1928, p. 41-77; et L. Lopetegui, San Francisco de Borgia y el plan misional de San Pio V, dans AHSI, 11,1942 , p. $1-25$

${ }^{5}$ L'Église romaine cherchait alors, dans le cadre de l'évolution générale de la Contre-Réforme, à "normaliser» les institutions fondées dans les décennies précédentes, en particulier celle des clercs réguliers (voir, sur Paul IV et son pontificat, la synthèse récente de A. Aubert, Alle origine della Controriforma : studi e problemi su Paolo IV, dans Rivista di storia et letteratura religiosa, 22, 1986, p. 303-355). 
quelque chose, non seulement des enjeux de la relation entre le pape et les jésuites par rapport aux missions, mais de l'enjeu des missions par rapport à la relation entre le pape et les jésuites : les missions sont aussi un moyen d'obtenir quelque chose du pape - et le texte de 1558 peut aussi être lu à cette échelle.

Mais dans le même temps, le document de 1558, quelques mois avant la première congrégation générale des jésuites, n'est que la première d'une série de prises de positions institutionnelles sur la question des missions dans le long terme. Il n'y a pas de décret sur les missions dans la congrégation de mai-juillet 1558, comme si le texte qui nous occupe n'était pas d'abord un document préparatoire, ou comme si, en tant que tel, il n'avait pu être retenu : l'articulation de ces deux lectures, "synchronique» et "diachronique", traversera toutes nos interrogations; mais la trame du texte de 1558 peut être repérée et suivie dans toute une série d'autres textes (instructions générales et mémoires de congrégations provinciales, jusqu'à la cinquième congrégation générale de 1593, date d'achèvement du processus d'élaboration des textes constitutionnels de l'ordre).

Le texte de 1558 nous a intéressé, dans sa sécheresse, ses ellipses et son urgence, au croisement de ces deux axes, comme une sorte de «fleur japonaise", dont nos analyses se sont attachées à déployer le sens. C'est un texte descriptif/prescriptif, sans équivalent dans la littérature des autres grands ordres missionnaires à la même époque. La Compagnie de Jésus est un ordre jeune, qui "aligne» ici un premier bilan en même temps qu'il esquisse la définition d'une politique; c'est un texte partiellement indéterminé, soit dans ses formulations (ce sera par exemple le cas des «relais indigènes" - qui ne désignent qu'indirectement l'énorme question de la formation d'un clergé indigène), soit dans ses décisions. Il s'agit surtout pour ce texte d'énoncer, à l'échelle de la planète, un certain nombre d'alternatives, que la Compagnie de Jésus est à ce moment-là bien placée pour poser qu'elles aient ou non déjà été de fait tranchées sur le terrain, comme nous l'a montré l'exploitation de la littérature administrative jésuite des années 1550-1600. Nous proposons dans cet exposé à plusieurs voix les principaux résultats de cette enquête, selon trois grand chapitres :

1) l'insertion des missions dans la société coloniale, données sociales, économiques et politiques du développement des premières missions jésuites hors d'Europe;

2) un "clergé missionnaire»: recrutement, formation, formes d'implantation et d'insertion ecclésiastique des personnels missionnaires. L'enquête, comme on le verra, a dicté plusieurs priorités, comme par exemple la question, largement développée, de l'apprentissage des langues; 
3) l'institution missionnaire : le fonctionnement de la Compagnie de Jésus en tant qu'ordre missionnaire, où plusieurs problèmes apparemment très “administratifs» seront évoqués, qui ne prennent leur sens que par rapport à la contextualisation tentée - d'où une progression de nos développements de l'extérieur vers l'intérieur de l'ordre.

\section{L'INSERTION DES MISSIONS DANS LA SOCIÉTÉ COLONIALE}

\section{Le problème de la conversion}

Les missionnaires jésuites ont pris pied ou sont tout près de le faire sur presque toute la surface de la terre dès la fin des années 1550 : au Brésil, en Inde, en Chine, en Afrique, en Amérique hispanique - régions citées ici, comme généralement dans notre document, selon un double ordre chronologique et apostolique. On distingue d'une part les territoires investis ou à investir (l'Amérique hispanique par exemple, visée en 1558, mais abordée plusieurs années plus tard, en 1566 par la Floride, puis par le Pérou en 1568), d'autre part (comme par exemple au § 7) les pays qui doivent être conduits à la foi (ad fidem trahendos) ou qui sont disposés à la foi (dispositi ad fidem). Or cette différenciation importante s'effectue sur le fond d'une autre différenciation effectuée par le texte - d'une évidence telle qu'il nous semble important de la signaler - entre la conversion des infidèles d'une part, à laquelle la totalité du document conservé est consacrée et, d'autre part, la «réduction des hérétiques" et la "perfection" des catholiques. Or l'on sait que la conversion des indigènes n'est pas la seule tâche des missionnaires, et qu'elle n'a même souvent, à l'origine, nullement été leur tâche principale, qui était, précisément, la "perfection» des peuples colons. La conception même du document est donc déjà, en amont des distinctions "fines» entre les peuples incroyants et les peuples attachés à d'autres croyances, un parti pris sur la définition même de l'espace colonial comme terre de mission (P. A. F.).

\section{Missions et sociétés coloniales}

En 1558, année de la première congrégation générale et donc de la rédaction du document qui nous occupe, la Compagnie de Jésus peut déjà compter sur une expérience de seize années d'apostolat dans les colonies portugaises des Indes orientales et occidentales. Les deux missions de l'Inde et du Brésil se sont insérées rapidement dans la vie politique et économique de ces colonies, en vertu du padroado et des concessions ob- 
tenues depuis la fin du XV' siècle auprès de la papauté par les souverains portugais, qui faisaient de la vie religieuse des colonies une affaire exclusive de la couronne. Cela signifie que toute réflexion sur la question des relations entretenues par la mission avec les autorités coloniales passent par le cadre portugais, les missions du Maroc ou du Congo n'ayant aucune existence institutionnelle à ce moment. La question des "Indes soumises au roi Philippe ${ }^{\circ}$ ne peut être tenue, quant à elle, à ce moment, que pour un horizon, sans que ces «Indes» puissent fournir de données plus précises.

Il s'agit donc de mesurer la position tenue dans ce contexte par ce qui apparaît comme l'un des premiers documents préparatoires sur les missions de la Compagnie. Ce genre de texte se trouve exactement au point de convergence de deux séries documentaires. Il est d'abord élaboré à partir de la remontée de toutes les informations par le canal des lettres et rapports qui affluent vers Rome. Il se propose ensuite de servir d'ébauche pour des textes normatifs ultérieurs, adressés à toutes les missions, assortis des lettres et instructions particulières qui les commentent et les adaptent. Nous verrons que le texte de 1558 traduit avec beaucoup de retard et d'imprécision l'expérience des missions ultramarines portugaises, dont il donne une représentation abstraite et déjà largement caduque. De plus on constatera que le sacrifice fait à une formulation générale et consensuelle rendra le texte inapte à décrire, comme à produire, une vision cohérente des relations de la mission avec son environnement colonial.

Le texte évoque explicitement des pans entiers du monde laïque, les "gens du dehors", tels qu'ils sont nommés de manière générique dans le $\$ 14$. Nous trouvons d'abord les «habitants des Indes les plus proches de nous» (\$ 2 et 17), c'est-à-dire les chrétiens susceptibles d'entrer dans la Compagnie; puis les néophytes $(\S 5)$, les nouveaux convertis, donc des indigènes; ensuite les "Brésiliens" et les "Chinois" ( $\$ 7$ et 19), donc les Indiens; puis les enfants $(\$ 10)$, les enfants d'Indiens ou de Portugais indifféremment; ensuite «les gens du dehors» (\$ 14), c'est-à-dire tout le monde; puis "les chrétiens", les Portugais corrompus ( $\$ 20)$; enfin le vice-roi des Indes $(\S 20)$. Nous reconnaissons là l'approche livrée par tous les documents de missionnaires, celle d'une société perçue à travers un découpage, dont le

${ }^{\circ}$ L'expression se trouve employée au $\S 7$ dans notre document. On réfléchit alors sur les moyens de parvenir jusqu'aux terres espagnoles d'Amérique. Le problème concerne la mission brésilienne qui demande instamment l'autorisation d'entrer au Paraguay pour, de là, parvenir au Pérou. Cette autorisation sera refusée par Philippe II jusqu'en 1585. 
critère descriptif est le degré d'éloignement par rapport à la mission. Les chapitres qui évoquent la situation des divers groupes sociaux réfléchissent tous à la possibilité et à la nature du lien qui doit les unir à la mission. Le $\S 2$ dispose de manière géométrique cette attitude?

La pratique évangélique contredit quotidiennement cette vision. La porosité de la société et l'attraction progressive de ses éléments par la mission relèvent d'un modèle qui ne correspond déjà plus, et cela de manière évidente dès 1552, à la réalité à laquelle les missions se confrontent. La société coloniale n'est plus perçue que comme une force d'opposition face à laquelle il n'existe qu'une stratégie, l'action auprès des gouvernants. Le cas du Brésil est certainement le plus désespéré. Un texte comme le «Dialogo sobre a conversao do gentio", daté de la fin de l'année 1556, est une parfaite illustration de l'hostilité définitive ressentie par les missionnaires ${ }^{8}$. Alors que le texte de 1558 propose encore des accommodements ${ }^{9}$, au $\S 17$, avec les "habitants de ces régions", c'est-à-dire les Portugais et des métis qui peuvent éventuellement être acceptés dans la Compagnie au rang de coadjuteur temporel, les missions brésiliennes et indiennes ont déjà abandonné cette stratégie, après l'avoir pratiquée à leur arrivée, en 1549 au Brésil et 1542 en Inde ${ }^{10}$. De la même manière, au $\S 19$, pour les indigènes qui pourraient être utilisés à la conversion des autres sans être intégrés formellement à la Compagnie (sans prononcer les trois voux), il semble que la position du texte de 1558 dessine des attitudes contradictoires ${ }^{11}$, en posant une frontière définitive entre la Compagnie et les indigènes, "bien qu'ils n'appartiennent pas à la Compagnie» (§ 19), tout en niant ce qui est alors la réalité pour les jésuites sur le terrain, c'est-à-dire l'irréductibilité des indigènes à la foi chrétienne. Ces deux exemples montrent les contradictions

7 «Qui etiam accommodari possint constitutiones et regulae, ad captum eorum qui vivunt in illis regionibus ut etiam provideat ut nostri sic proximorum subventioni dent operam, ut ipsi conservari in utroque homine possint, immo et augeri (ubi hominum indigenorum ingenium id feret) spiritu et numero studeant "(voir la traduction en annexe).

${ }^{8} M B$, II, p. 319-345.

9 "Videatur an ex incolis illarum regionum aliqui apti reddi possint ad institutum nostrae societatis suscipiendum»(§17).

${ }^{10}$ Manuel da Nóbrega, le futur provincial du Brésil, avait formulé, en 1552, la demande d'envoi de deux nouvelles recrues au Portugal pour y parfaire leur formation, évoquant leur retour ensuite sur le terrain brésilien. Cette audace n'a jamais été acceptée ni refusée explicitement mais elle n'eut de suite concrète que pour un seul jésuite, Cipriano, en 1555. Voir article de S. Leite, Cipriano do Brasil, primeiro jesuita filho da América, dans Verbum, IX, 4, déc. 1952, p. 469-476.

$"$ "Videatur an allii ex indigenis apti reddi possint ad conversionem et conservationem aliorum ...» (§ 19). 
internes du document, qui hésite entre deux images de l'action missionnaire et prêche un impossible aggiornamento.

L'hésitation se répète pour ce qui concerne la relation avec les gouvernements coloniaux, dont la faiblesse et la mauvaise volonté envers les jésuites est patente en 1558. Aux Indes orientales, les vice-rois Pedro de Mascarenhas (1554-1555) et Francisco Barreto (1555-1558) ne font pas preuve de beaucoup d'enthousiasme pour la Compagnie, à laquelle ils limitent les crédits. Au Brésil, le second gouverneur, dom Duarte da Costa, (1553-1557), n'assume pas son rôle de protecteur et de régulateur. Aussi la mission estelle réduite à défendre ses positions. Le document que nous examinons semble en tenir compte au $\S 20$ qui, après un intitulé sybillin ("Comment ceux qui sont à la tête font preuve de bienveillance à l'égard de leurs subordonnés»), évoque la médiation de la régente du Portugal, Dona Catarina, afin qu'elle incite les vice-rois à mieux soutenir et contrôler les chrétiens ${ }^{12}$. Mais la formulation du conflit interne entre les colons et les élites locales reste très générale et ne détermine en aucune façon les choix de la mission sur le terrain, puisqu'il ne propose qu'une action sur.la reine, donc hors de la colonie.

Le texte romain dans son ensemble exprime donc une réalité qui a au moins cinq ans de retard sur l'évolution de la mission brésilienne. De plus il semble adopter une position médiane qui paralyse son pouvoir de proposition en se contentant d'entériner ce qui fait figure, déjà en 1558, de cliché des colonies, le fait que ce sont "les chrétiens qui provoquent l'inhumanité et le défaut de charité» et que "la conversion des infidèles et le progrès de ceux qui étaient déjà convertis ont été jusqu'ici empêchés " ${ }^{13}$.

Cette imprécision est le résultat du manque d'informations d'ensemble mais surtout de l'absence d'un modèle spécifiquement adapté aux missions d'outremer. L'aspect pointilliste de la représentation concrète des cadres coloniaux coexiste avec l'abstraction de la structure générale qui pourrait dépeindre la plupart des sociétés laïques contemporaines. Le traitement des données spécifiquement coloniales est inexistant. Ce manque, faiblesse majeure du document, explique peut-être qu'il n'ait connu aucun développement ultérieur.

Le seul élément solide réside dans le fait qu'il ne considère le monde laïque que pour déterminer la posture que la mission doit adopter à son égard, pour tracer une ligne imaginaire qui règle les attitudes individuelles

12 "...ut prorex Indiae benignum se eis exhiberet, et alios praefectos humanos ac pios eis praeficeret» $(\S 20)$.

${ }_{13}$ "Quandoquidem per christianorum qui praesunt inhumanitatem, ac charitatis defectum, impedita fuit hactenus quorundam infidelium conversio" (§ 20). 
et collectives, les choix stratégiques et économiques, les implantations et le travail catéchétique. C'est dire qu'il faut regarder le texte comme un effort de définition des contours de la mission elle-même, et non de la société coloniale rejetée dans le vague et l'indéfinition. Cette société n'est plus alors que l'un des éléments définitoires parmi d'autres et le texte, dans son ensemble, retrouve sa cohérence interne, justement parce qu'il ne fait aucune place à la spécificité des sociétés.

Le tracé et le respect de la frontière entre monde laïque et missionnaires est, dès l'origine de la Compagnie, au centre de toutes les préoccupations de Rome. Ce fut le vecteur de tensions multiples, dès $1552^{14}$. Les missions ont, sur ce point, à se confronter à un paradoxe : elles doivent assumer au quotidien la contradiction entre la nécessité d'insertion économique dans la production de la colonie et l'œuvre spirituelle. Leur subsistance matérielle dépend officiellement du roi, mais dans la pratique l'insuffisance de cette aide les renvoie aux donations particulières des colons ou à leur propre capacité à financer l'œuvre évangélisatrice. En suivant cette dernière option, elles entrent en concurrence avec les colons cuxmêmes, qui tentent d'en contrôler les activités ou de les détourner à leur profit. Dans le premier cas de figure, la mission, à la recherche de sa sécurité matérielle, se mêle à la société coloniale et perd sa liberté de mouvement; dans le second, elle se tient à l'écart et doit pourvoir à sa subsistance de manière autonome pour travailler au salut des âmes, courant le risque de se compromettre dans la recherche du profit. Elle doit alors assumer les conflits ouverts avec le reste de la société dont elle devient un membre, agissant dans le champ politique et économique.

Chaque mission connaît, loin de Rome, une évolution différenciée et sans réelle linéarité, qui relativise toute chronologie sur la totalité du XVI siècle. Mais on peut tracer le spectre des différentes attitudes entre deux bornes essentiellement : d'une part les missions qui tenteront la constitution d'une structure autonome en dehors de la société coloniale après avoir constaté l'impossible consensus, comme au Brésil et, plus tard et plus radicalement encore, au Paraguay; d'autre part une insertion très poussée dans la société coloniale qu'il s'agit de pénétrer et de modifier, comme ce fut le

${ }^{14}$ La crise portugaise de 1552, "l'affaire Rodrigues", en fut certainement l'exemple le plus violent. En effet, la destitution du premier provincial du Portugal ouvrit la crise de la province portugaise, qui menaça l'ordre tout entier. Le noeud de l'affaire avait été le développement séparé de la province sous la tutelle du roi portugais Jean III et un éloignement progressif de Rome. Le remplacement de Simon Rodrigues par l'espagnol Diego Mirón eut toute les apparences d'une reprise en main. 
cas au Mexique à la fin du XVI" siècle. À ces deux extrêmes, Rome est opposée et cette réaction est sensible dans les réponses formulées à l'occasion des congrégations provinciales. En effet, que la mission choisisse l'une ou l'autre voie, celle de l'indépendance ou celle du rapprochement avec les institutions laïques, la tutelle romaine est menacée.

Le document de 1558 recherche de toute évidence un juste milieu, ou plus exactement oscille entre les deux options sans les dissocier ni les rejeter. D'une part il accepte le cadre du padroado, qu'il rappelle à ses devoirs (§ 5 et 20 ), mais d'autre part il insiste sur les moyens de contrôle propres à la Compagnie, comme le conseil $(\S 1)$ et les visiteurs et commissaires $(\S 2)$. Aux deux bornes du texte, nous retrouvons donc Rome et Lisbonne, éloignées l'une de l'autre et gardiennes respectives de l'équilibre. Le pouvoir du roi est tempéré aux $\$ 5$ et 20 , qui mettent en avant la faveur des princes et donc la dépendance des missions, et au $\S 11$ qui autorise dans une certaine mesure le développement de ressources propres (esclaves et troupeaux).

On peut donc relire le texte à la lumière de son désir de marquer la limite entre le dedans et le dehors de la mission. Les membres de la Compagnie sont de trois ordres : les missionnaires, dont les qualités et le mode de sélection sont évoqués au $\S 3$, une élite de Portugais qui, par leur nature d'européens, peuvent être «capable de supporter les règles de la Compagnie» (§ 17), les indigènes qui resteront dehors (§ 19). Nous avons donc une définition forte du jésuite et une entrée différencielle des gens de la colonie, la barrière étant d'ordre racial. Nous trouvons ensuite la question des relations avec l'Indien qui alternent entre la recherche de la proximité et le maintien de la distance. Le problème de la langue $(\$ 18)$, et plus généralement celui de la communication avec les gentils est celui de la proximité. Au-delà des problèmes particuliers, la question du chant ( $\S 13)$, celle de l'habitat séparé $(\S 6,10)$ celle plus institutionnelle du contact avec les Sarrasins $(\S 9)$ est la même partout et peut se résumer à trouver la bonne distance pour convertir sans risquer d'être contaminé par l'extérieur. Le chant, la langue, la présence même immobile devant les Sarrasins et le fait d'habiter hors des résidences, sont des modes d'approche et des outils de conversion; cependant la séparation à l'intérieur des résidences, et la condamnation du martyre, contact paroxystique $(\S 16)$, sont des rappels de la menace qui pèse sur le missionnaire qui consentirait à la promiscuité. En dernière analyse la vertu du missionnaire parfait, assortie de moyens efficaces de contrôle internes sont autant de verrous pour assurer la frontière.

En ce sens le texte de préparation à la première congrégation générale pose le problème fondamental de toutes les missions jésuites. Il revèle qu'en 1558, la question des missions est encore à l'état d'ébauche, qu'elle ne 
formule aucune stratégie claire et formalisée. Les hésitations sur la position à tenir indiquent une recherche d'équilibre qui n'a rien de spécifique à ces missions. C'est un texte qui enregistre le flou et qui se donne pour objectif principal la création d'une marge de proposition et d'ouverture, comme le prouve les formules introductives et les multiples conditions préalables à chaque décision ${ }^{15}$.

On peut néanmoins suivre la postérité du texte à travers les documents ultérieurs à partir des points de friction entre les missions et les sociétés coloniales qui constituèrent de manière massive la matière des échanges entre Rome et les missions après 1558, prouvant que le problème avait changé de nature. La nette radicalisation des textes normatifs fait écho aux évolutions variables sur le terrain. Les expériences locales ne pouvaient s'en tenir à l'équilibre abstrait, aussi les missions se sont-elles engagées dans des voies qui les ont amenées à basculer dans un sens ou dans l'autre. La régulation de ces "excès" est chose nécessaire dès l'origine. De fait ce n'est qu'avec l'accession de François de Borgia au généralat, en 1565, que le souci d'homogénéisation des pratiques missionnaires vient au premier plan. Mais l'inertie des pratiques, les circonstances locales et les résistances, parfois jusqu'à l'insoumission, rendront vaines la plupart des récriminations romaines. Cela eut pour conséquence la répétition permanente des mêmes admonestations durant tout le XVI ${ }^{e}$ siècle.

Pour chaque point, le scénario est d'une remarquable netteté. Rome a autorisé et encouragé, de manière générale, les médiations entre la société coloniale et la mission. Dans un second temps la mission s'installe dans une pratique, qui n'est en général repérable qu'en creux dans les documents, et enfin, dans les textes venant de Rome, interviennent les corrections explicites. Je n'évoquerai ici qu'un seul exemple, celui des médiations dans les conflits entre laïques, l'un des plus récurrents et des plus significatifs.

Ce type de situation, qui met en contact de manière directe la mission et l'ordre laïque, illustre le type d'attitudes contradictoires adoptées par les jésuites. Ces derniers, n'ayant ni cure d'âme ni responsabilité dans la vie institutionnelle, occupent a priori une position d'extériorité dans le

${ }^{15}$ La plupart des chapitres sont introduits par les formules "considérer si", "voir si». De plus les décisions éventuelles sont soumises à des conditions suspensives sur lesquelles la congrégation générale ne peut statuer. Ainsi le problème de l'enrôlement des indigènes dans la catéchèse au $\S 2$ est-il suspendu à la parenthèse "lorsque leur aptitude naturelle les y portera", ce dont seule la mission elle-même peut juger. 
contexte colonial. Cela les rend aptes à intervenir comme médiateurs dans les conflits. Il s'agit là d'une source non négligeable de prestige qu'Ignace ne négligea d'ailleurs pas. Le prestige étant une valeur monnayable immédiatement auprès des élites locales, tous les moyens d'en acquérir sont bons. Car dès l'origine des missions, il convient de rechercher les donations, les bonnes volontés largement aléatoires ne pouvant en aucun cas suffire à la maintenance des résidences. Cependant ces interventions comportent un risque d'ingérence et donc d'enrôlement dans les conflits. Aussi chaque congrégation rappellera-t-elle la règle de la mesure et de l'équilibre en ce domaine comme dans toutes les activités sociales de la mission sans affronter le problème d'une action nécessaire, mais répréhensible. La mission doit, elle, trancher rapidement et s'investira massivement dans la fonction de médiateur au sein de la colonie. La contradiction repose sur le fait qu'en exerçant ce rôle, la mission perd la neutralité qui en était la condition sine qua non. De cela le document de 1558 ne dit rien, sinon qu'il faut "rechercher la faveur des princes» (§ 5). Ce type de problèmes, comme d'autres aussi ${ }^{16}$, ne sont jamais abordés et laissent la mission affronter les circonstances sans règlement ni certitude, justifiant les rappels à l'ordre constants mais autorisant aussi toutes les négociations.

Le document de 1558 propose une image des relations entre jésuites et sociétés coloniales qui n'intègre qu'imparfaitement les premières expériences de terrain. Mais il est la matérialisation du hiatus entre Rome et les missions lointaines, la première se révélant incapable de produire une règle cohérente et utilisable à l'usage des secondes. Les missions demanderont toujours plus d'autonomie afin de réagir immédiatement aux circonstances, Rome étant avertie après coup et condamnée soit à entériner les décisions soit à tenter de les corriger. Ce décalage est chronique pendant tout le XVI* siècle en Amérique, et il explique que les documents jésuites les plus riches soient les textes régressifs qui reviennent sur les pratiques, alors que les documents programmatiques restent souvent plus sybillins (J.-C. L.).

${ }^{16}$ Nous aurions pu évoquer les contrats de fondation des collèges, nécessaires mais lors desquels il est souvent difficile d'éviter les ingérences manifestes des donateurs. Le cas des enterrements dans les églises jésuites, celui des mariages dont les pères organisent et garantissent les contrats, sont autant d'interpénétrations entre les deux mondes. Cela constituera l'essentiel des avertissements, des conseils de prudence et des menaces de sanction de Rome. 


\section{Le financement de l'entreprise missionnaire}

Les sources de financement des missions jésuites sont multiples et proviennent d'origines diverses. Pour toute la période 1540-1750, elles peuvent être groupées en cinq catégories différentes :

1) La couronne, dans le cadre du padroado, intervient surtout par le biais des aumônes. Mais elle participe aussi au travers de formes de financement indirects, comme par exemple l'exemption ou le reversement d'impôts, éventucllement avec autorisation d'en faire bénéficier ensuite des particuliers. La couronne procède également à des donations de terres, mais rarement selon le régime de sesmaria (qui signifie l'obligation de rendre la terre productive dans l'espace de quelques années, sous peine de perte du droit de propriété). Elle propose enfin des compensations matérielles en échange des charges extra-spirituelles que la Compagnie de Jésus se dispose à assumer, en l'absence d'un personnel adéquat dans les possessions portugaises (comme c'est le cas, par exemple, pour la gestion des hôpitaux ou la frappe de la monnaie en Inde).

2) La Compagnie de Jésus reçoit également des donations de la part de bienfaiteurs particuliers, indifféremment grands propriétaires, nobles, ecclésiastiques ou petits donateurs.

3.1) La Compagnie de Jésus reçoit des terres ou des immeubles, en donation, en échange ou en héritage. Terres ou immeubles peuvent aussi faire l'objet d'une politique d'achat direct de la part de la Compagnie. Dans les villes, les immeubles sont souvent destinés à la location, lorsqu'ils ne sont pas occupés par les missionnaires. Les terres sont mises à profit par le fermage, l'élevage de bétail et la culture de produits destinés à la consommation intérieure ou à l'exportation. Si la location des immeubles dans les villes rapporte beaucoup à la Compagnie, et constitue l'une de ses principales sources de revenu, la culture de la terre ne génère, en revanche, que des marges de profit très étroites.

3.2) La Compagnie gère également un patrimoine d'embarcations diverses, de bétail et d'esclaves, acquis selon les procédures communes, donation, échange, héritage ou rachat. Il est à noter que, d'après les inventaires dressés par les jésuites dans des terres de mission comme le Brésil, le Pérou ou le Mexique, la main-d'œuvre esclave est nettement plus nombreuse que celle des salariés libres ou des coadjuteurs temporels (la catégorie inférieure de l'institution jésuite, attachée aux travaux matériels).

4) Les jésuites s'emploient aussi au commerce : ils commercialisent des drogues diverses, comme le tabac et le sucre, des denrées alimentaires pour les marchés intéricurs, ou encore du rhum, de la soie, des diamants, etc. 
5) Enfin, les jésuites développent tout au long de cette période un système complexe de prêts et de crédits, aussi bien à l'intérieur de la Compagnie qu'à l'extérieur. Le roulement des dettes permet souvent aux divers collèges de se lancer dans des entreprises commerciales audacieuses, tandis que la perception d'intérêts constitue, avec les locations et les fermages, une source importante de revenus. Un même collège jésuite peut être à la fois créancier et débiteur ${ }^{17}$.

Dans le document rédigé en 1558, il est notamment question de la propriété des esclaves et des troupeaux (\$11), dont la légitimité et l'opportunité firent l'objet d'importantes polémiques à l'intérieur de la Compagnie. Le cinquième paragraphe, dédié à la faveur des princes, évoque les retombées économiques de la dîme ${ }^{18}$, problème lié à celui de la gestion des hôpitaux (§ 14), puisque c’est avec le Prince que les jésuites négocient les conditions des charges temporelles qu'ils assument dans les possessions portugaises. Le recrutement d'auxiliaires en tant que coadjuteurs temporels, l'érection de maisons et de collèges, la garde des enfants dans les maisons et l'habitation des profès dans les collèges $(\$ 6,10,15,17$ et 19) sont autant de questions spécifiques rattachées par ce document à celle, générale, des bases matérielles de subsistance des missions. Toutes renvoient donc, en dernière instance, au problème du financement de l'entreprise missionnaire jésuite, une entreprise économiquement improductive, qui dépend donc fortement de l'État et des donations des bienfaiteurs. La gestion des hôpitaux, par exemple, est en principe contraire à l'esprit des Constitutions :

Pour que la Compagnie puisse s'employer plus entièrement aux choses spirituelles propres à sa profession, elle abandonnera, autant que faire se pourra, toutes «les affaires séculières».

Les Déclarations ajoutent à ce point :

On observera cela autant que possible, le pouvoir étant au supéricur d'en dispenser provisoirement pour des cas de nécessité ou pour des questions importantes par rapport à la fin que l'on poursuit, qui est le service divin ${ }^{19}$.

${ }^{17}$ Une mise au point récente de la politique économique de la Compagnie de Jésus au niveau de l'Assistance portugaise a été faite par l'historien D. Alden dans The making of an enterprise. The Society of Jesus in Portugal, its Empire, and beyond: 1540-1750, Stanford, 1996, p. 319-567.

${ }^{18}$ Comme le rappelle D. Alden, "a series of exemptions [are] issued by popes Paul III, Pius IV, and Gregory XIII between 1549 and 1578", op. cit., p. 462. Certaines de ces mesures suivent les recommandations du concile de Trente.

${ }^{19}$ Constitutions [591], dans Ignace de Loyola, Écrits, éd. M. Giuliani, Paris, 1991, p. 539. 
Au-delà d'une dimension morale évoquée dans le $\S 14^{20}$ la gestion des hôpitaux permettait en fait de monnayer les aumônes royales. En Inde, par exemple, dont le cas est discuté dans le texte de 1558, c'est contre les avis de François de Borgia ${ }^{21}$ et d'Everard Mercurian"22 (qui n'y voient pas un "cas de nécessité") que les jésuites assumeront la responsabilité de l'hôpital militaire royal. Sous la pression de Philippe II, les missionnaires acceptent définitivement en 1591 cette charge, garantie par les fonds provenant des taxes sur l'alimentation, le savon et l'opium, et construisent un nouvel hôpital en 1594-1598. Quoique ces subventions ne soient jamais réellement assurées, les jésuites garderont la charge de l'hôpital jusque dans les années $1750^{23}$.

Ces disjonctions entre les directives romaines et les pratiques sur le terrain sont plus évidentes encore en ce qui concerne la question de la propriété des esclaves et des troupeaux. Le choix d'acquérir ou non des esclaves et des troupeaux dans le cadre d'une stratégie d'autofinancement des missions fait effectivement l'objet d'une longue polémique à l'intérieur de la Compagnie ${ }^{24}$.

Quand la question est posée dans le texte de 1558 («considérer s'il doit être permis..."), des demandes d'achat d'esclaves ont déjà été formulées un peu partout ${ }^{25}$ et le recours à la main-d'œuvre esclave est une pratique courante dans plusieurs établissements jésuites, notamment au Portugal et au Brésil.

20 «(...) les gens du dehors n'étant pas de confiance, (...) afin de faire des meilleures preuves et d'être d'une plus grande édification envers ces mêmes gens (...) si nul n'est fiable, que l'on puisse assumer nous-mêmes la charge».

${ }^{21}$ Indiarum inspectori instructio, dans $B M$, IV, p. 383-384.

${ }^{22}$ Responsa R. P. Everardi Mercuriani Praep. Gen. S. I. ad Congregationem Primam Provinciae Indicae (31 janvier 1577), § 31, dans DI, X (De nosocomio in Salsete). Voir également les Acts of the Third provincial Congregation of India with the answers of Fr. Cl. Acquaviva» (Goa, 24 octobre - 5 novembre 1588, Rome, juillet 1590), § 25, dans DI, XV, et le Memorial of Fr. Pedro Martines S.J., provincial, with the answers of Fr. Claudio Acquaviva (Goa, novembre 1588, Rome, août 1590), § 2, dans DI, XV.

${ }^{23}$ Les jésuites gèrent des hôpitaux à Malacca, au Japon (à Funai), au Brésil (une "pharmacie" à Salvador, qui apporte entre 3\% et 10\% des revenus annuels de la province), au Portugal (à Coimbra et à Évora) et en Inde (à Salsete, à Margão et à Goa). Toujours dans la région de l'Inde, ils assument également l'administration des forts - de Bassein, Chaul, Damão, Diu, Onor et Mozambique, ainsi que la gestion des réserves de grain, et même la frappe des petites monnaies en cuivre (les bazarucos ou bousurque).

${ }^{24}$ Voir C. Zerón, La Compagnie de Jésus et l'institution de l'esclavage au Brésil (thèse de doctorat soutenue à l'EHESS, 1998).

${ }^{25}$ Voir, par exemple, la lettre de François Xavier à Gaspard Barzée, Goa, avril 1552, dans $M X, \mathrm{I}$, p. 903-904. 
Le cas du Brésil est évoqué explicitement en 1558, et mérite effectivement qu'on s'y attarde. Quoique la hiérarchie jésuite à Rome soit au courant de l'utilisation de la main-d'œuvre esclave au Portugal dès les années quarante $^{26}$ la mention du problème brésilien renvoie en fait à l'inquiétude romaine face aux stratégies que l'on commence à développer dans les terres de mission, la recherche de sources de financement stables, et autonomes par rapport aux aléas des faveurs royales : une politique d'autofinancement des missions est envisagée, au Brésil particulièrement, comme le seul moyen d'expansion de la mission jésuite. La discussion de l'aspect économique des missions à Rome est certes en retard par rapport à la pratique sur le terrain, mais elle est toujours d'actualité : c'est ce qui motive l'inclusion de cette question dans divers paragraphes du document de 1558 $(\S 5,6,10,11,14,15,17$ et 19$)$, préparatoire à la première congrégation générale. Le cas du Brésil, dont la politique pastorale jésuite affronte les contradictions et les limitations inhérentes à son insertion dans une société coloniale en formation, est envisagé ici comme un cas exemplaire, et c'est en ce sens qu'il est cité.

Il reste cependant que la première congrégation générale ne se prononce pas sur cet aspect particulier ${ }^{27}$ : cela reviendra au général de l'ordre quelques années plus tard. Ainsi, après les premières demandes d'achat d'esclaves et de bétail formulées au Brésil ${ }^{28}$, Diego Laínez (général de l'ordre de 1558 à 1565) donne son approbation, ne voyant pas de contradiction avec les Règles et les Constitutions de l'ordre ${ }^{29}$.

Son successeur François de Borgia (1565-1572) annulera cependant cette décision. Dans l' «Instrucción para el Pe. Inacio de Acebedo en la visitación de la Provincia del Brasil»(24 février 1566), il demande au visiteur :

${ }^{26}$ Voir, par exemple, la lettre que le provincial du Portugal, Simão Rodrigues, écrit à François Xavier en 1547, dans laquelle il raconte comment le collège de Coimbra est construit avec l'aide de dix esclaves donnés par le roi.

${ }^{27}$ Voir J. W. Padberg et al., For matters of Greater moments. The first thirty General Congregations, St. Louis, 1994.

${ }^{28}$ Voir les lettres suivantes : Manuel da Nóbrega à Simão Rodrigues, 9 août $1549(M B$, I, p. 126), Manuel da Nóbrega à Jean III, 14 septembre 1551 (MB, I, p. 293), et Manuel da Nóbrega à Simão Rodrigues, 10 juillet 1552 (MB, I, p. 351-2). Cette dernière lettre n'est plus une demande : elle informe de l'achat de quelques esclaves et d'une douzaine de vaches, pour lequel un remboursement est demandé (ce qui est confirmé ensuite par deux provisions royales).

${ }^{29}$ Voir la lettre de Diego Laínez à Antonio de Quadros, 31 décembre 1560 ( $L M$, V, p. 360) et celle qu'il adresse directement à Manuel da Nóbrega le 16 décembre 1562 (LM, VI, p. 578). 
Voyez comment ils procèdent en matière de revenus (élevage de troupeaux et ce genre de choses) et comment ils assurent leur subsistance, et ce qu'il conviendrait de faire dans ce domaine. Et si quoi que ce soit de ce ce qu'ils font là-bas vous semblait directement contraire à notre Institut, proscrivez-le. J'en fais pour vous une affaire de conscience ${ }^{30}$.

Ensuite, dans une autre lettre adressée au même visiteur, datée du 30 janvier 1567, alors que celui-ci se trouvait déjà au Brésil, on perçoit comment les positions de François de Borgia se rapprochent des positions ascétiques de Luis da Grã, successeur au poste de provincial du principal stratège de la politique d'autofinancement au Brésil, Manuel da Nóbrega :

Élever du bétail ou toute autre chose de ce genre ne convient nullement à notre Institut, parce que cela tient d'une affaire marchande; la Compagnie en a décidé ainsi dans sa congrégation, comme vous le savez, sauf pour ce qui touche à la subsistance alimentaire des nôtres : mais s'il s'agit de cultiver ou d'élever quelque chose pour le vendre, alors cela ne va pas ${ }^{31}$.

Au Brésil, en dépit de l'opposition du provincial et des tentatives de contrôle de la hiérarchie romaine par l'intermède du visiteur, la première congrégation provinciale (1568) postule :

Le collège et les maisons peuvent et doivent avoir les vaches et les esclaves qui leur seront nécessaires, s'ils n'ont pas d'autres moyens de subsistance $^{32}$.

Après avoir pris connaissance de ces décisions, que le visiteur Inacio de Azevedo rapporte en personne à Rome en tant que procureur des mis-

30 «Instrucción...», 24 février 1566 (MB, IV, p. 326) : «Mire el modo que tienen quanto a la renta, como de vacas y otras semejantes industrias, y manera de sustentar-se, y lo que conviendría procurar en esta parte; y si alguna cosa de las que se usan allá le pareciere derechamente contraria a nuestro Instituto, quitela, para lo qual le encargo la conscientia». La visite de Inácio de Azevedo dure du 23 août 1566 au 14 août 1568 .

${ }^{31}$ François de Borgia à Inácio de Azevedo, 30 janvier 1567 (MB, IV, p. 376-7) : «Tener criança de vacas o otras semejantes granjerías, no conviene a nuestro Instituto, porque tiene specie de negociación mercantil, y así lo proveyó la Compañía en la Congregación, como V. R. sabe, si no fuese lo que es menester para su comida de los Nuestros; pero cosa que se aya de crear para vender, como digo, no es a propósito (...)". La deuxième congrégation générale, qui examine finalement ces questions, a lieu du 21 juin au 3 septembre 1565. Voir aussi la lettre de François de Borgia à Inácio de Azevedo du 22 septembre 1567 (MB, IV, p. 417).

32 "Postulados da Primeira Congregação provincial do Brasil», Bahia, juin 1568, $\$ 10(M B, \mathrm{IV}$, p. 467). La visite de Inácio de Azevedo, qui se conclut en juillet de la même année, confirme cette décision : voir "Visita da Província do Brasil pelo P. Inácio de Azevedo», MB, IV, p. 484. 
sions à Rome et à Lisbonne (poste pour lequel il est élu lors de cette même congrégation provinciale), François de Borgia revient définitivement sur sa position initiale et confirme finalement la décision de Diego Laínez ${ }^{33}$.

Les décisions prises au Brésil lors de la congrégation de 1568 font état d'une fuite en avant des missions brésiliennes, à travers une politique d'autofinancement par le fermage et par l'exploitation directe des terres leur appartenant. La production d'excédents agricoles, pour le commerce à l'intérieur de la colonie comme avec la métropole ou avec les autres possessions portugaises, prend alors des proportions importantes. En 1590, après de longues hésitations, Claudio Aquaviva autorise finalement les plantations de canne à sucre. Mais les missionnaires au Brésil, en dépit de quelques oppositions internes, se préparaient déjà à s'engager dans cette culture sans attendre la décision du général ${ }^{34}$. Au début du XVII ${ }^{*}$ siècle, ceci est déjà une réalité : les premiers registres de la production de sucre par les missionnaires remontent au mois d'août 1601, dix ans après l'initiative équivalente de leurs collègues en Nouvelle Espagne.

La question du financement des missions, qui apparaît en filigrane dans plusieurs paragraphes du texte de 1558, n'est finalement pas discutée dans la première congrégation générale, et restera longtemps suspendue. Cela relève probablement d'une hésitation, au niveau de la hiérarchie romaine, à cautionner la stratégie d'autofinancement des missions mise en œuvre par des provinces telles que le Brésil. La vingtaine de pères réunis à Rome en 1558 semble préférer renvoyer la décision à d'autres autorités, en particulier aux théologiens en exercice dans les universités de Coimbra et Évora, et ce même si l'ajournement d'une décision risque de causer de graves divisions à l'intérieur de la Compagnie, par exemple au Brésil.

En janvier 1566, François de Borgia répond ainsi aux objections formulées par le provincial du Brésil, Luis da Grã, quant à la politique d'autofinancement engagée par la gestion de son prédécesseur, Manuel da Nóbrega :

De la difficulté qu'il y a à assurer la subsistance des nôtres en élevant du bétail, il faut traiter avec le visiteur. Pour ce qui est de la canne à sucre, il ne semble pas que cela puisse être une bonne chose. Il faut que l'on se penche

${ }^{33}$ Archivum romanum Societatis Iesu [désormais ARSI], Congr. 41, fol. 299v.

${ }^{34}$ Voir, entre autres références, D. Alden, The making of an enterprise cit., p. 416-29; S. B. Schwartz, Sugar plantations in the formation of Brazilian society, New York, 1985, p. 229-34 et 489-97; V. L. Amaral Ferlini, $O$ engenho Sergipe do Conde, 1622-1653. Contar, constatar e questionar, thèse dact., São Paulo, 1980; S. Leite, História da Companhia de Jesus no Brazil, Lisbonne, 1938-1950, vol. 2, I. I, c. 5 . 
au Portugal sur le problème des esclaves et de leur rachat, et l'on vous enverra la réponse au Brésil, et que l'on recommande cette réponse, une réponse qui fasse autorité, en s'y prenant de telle sorte que ceux de là-bas comprennent que ce n'est pas par scrupule, mais parce que la justice et la raison le veut ainsi, que les nôtres leur disent ce qui leur revient de faire ${ }^{35}$.

Or, le visiteur approuve l'élevage de bétail, et les théologiens cautionnent la jurisprudence en vigueur sur les pratiques de réduction d'autrui en esclavage. Cela finit par légitimer indirectement les politiques d'autofinancement des missions, contre les instructions ultérieures de la hiérarchie jésuite à Rome. L'autorisation de la culture de la canne à sucre n'est plus alors qu'une question de temps.

En dépit du renvoi de la décision à des autorités telles que le visiteur ou les théologiens par Borgia, il est à remarquer néanmoins que le $\S 11 \mathrm{du}$ document de 1558 mentionnait déjà ouvertement la possibilité de "donner aux provinciaux la faculté d'accorder des dispenses par rapport aux Constitutions et aux Règles et d'adapter ces Règles aux lieux et aux personnes". La réalité socio-économique des terres de mission - où les aumônes royales sont rarement payées, et les dons particuliers bien maigres parce que la population d'origine européenne est soit misérable, soit en conflit avec la Compagnie de Jésus - affecte en effet bon nombre de principes et de règles de l'ordre, les accommodant aux besoins matériels les plus pressants. Face à des circonstances souvent hostiles, quand les règles ne suivent pas, la politique en terre de mission tend tout simplement à les ignorer.

Par ailleurs, considérant les hésitations de la hiérarchie à Rome, et considérant également les dispenses qu'elle s'empresse d'accorder aux provinciaux, il est légitime de se demander jusqu'à quel point les membres qui s'y réunissent en congrégation ne partageaient pas finalement une analyse de la question du financement des missions proche de celle que nous retrouvons, majoritaire (pour ne pas dire hégémonique), dans les terres de mission (C. Z.).

${ }^{35}$ François de Borgia à Luis da Grã, 10 janvier 1566 (MB, II, p. 291-2) : «la difficuldad que ay en el modo de sostentarse los nuestros criando vacas, tratarse ha con el Visitador. Lo de las casas de azùcar no paresce cosa conveniente. Estudiarse ha en Portugal la difficuldad de los esclavos y su rescatte, y la resolución se les embiará al Brasil, que assí se les encomienda, y que sea cosa que tenga autoridad, para que allá se entienda que los nuestros, no por ser scrupulosos, sino porque assí lo pide la justicia y razón, les dan aviso de lo que les cumple». 
UN CLERGÉ MISSIONNAIRE

Sédentarisation des missions et apprentissage des langues

Il faudrait aussi que les nôtres envoyés depuis l'Europe apprennent les langues de cette sorte de nations, et qu'ils aient recours à leur art et à leur usage, s'ils sont vraiment estimés doués à cet égard (§ 18).

On reconnaîtra une hésitation, une irrésolution concernant l'apprentissage des langues vernaculaires non européennes par les missionnaires jésuites, dans le document de 1558 tel qu'il nous parvient. Si, au début du paragraphe, la prescription semble claire et autoritaire, l'auteur, en introduisant la variable de la disposition naturelle ou du talent [indole ad id] pour les langues, ouvre pour finir le champ à divers usages et lectures de ce fragment.

Nous nous efforcerons néanmoins de montrer qu'en ce qui concerne le problème linguistique, ce document de 1558 représente l'aboutissement d'une intense et vigoureuse concertation entre les missionnaires jésuites outre-mer et les autorités en Europe. Même si la première congrégation générale n'allait pas discuter dans le détail le contenu du $\S 18$, les faits ultérieurs prouvent qu'après 1558 , avec ou sans talent linguistique, l'apprentissage des langues vernaculaires non-européennes faisait partie de l'éducation missionnaire.

Ainsi, le général François de Borgia, durant son mandat (1565-1572), allait encourager tout effort linguistique. Dès son élection, Borgia conseille à Antonio de Quadros, provincial de l'Inde, d'organiser l'enseignement des langues indigènes "de maior emportancia» dans le collège de Goa, ainsi que d'envoyer au Portugal les "vocabulaires" ou les "méthodes " (algùn vocabulario o método) pour que les missionnaires destinés aux missions indiennes puissent être instruits en amont et d'une manière plus approfondie $^{36}$. Avec Everard Mercurian (1573-1580) débute la véritable offensive linguistique des missionnaires, consciemment liée en l'occurrence à la méthode ancienne, mais redécouverte, de l'accommodatio, dont la maxime "omnibus omnia factus sum» (1 Cor. 9,22) surgit dans la lettre du général à la province de l'Inde au détour d'une paraphrase tout à fait moderne. Mercurian écrit qu'il faut "être pris pour un d'eux» et "devenir enfant pour profiter aux enfants et aux illettrés [idiotas]», ce qui est impossible sans la connaissance parfaite des langues. En outre, Mercurian ajoute que «Dieu

${ }^{36} \mathrm{DI}, \mathrm{VI}, \mathrm{p} .528$. 
notre Seigneur contribuera par son propre très grand pouvoir de grâce " à l'accomplissement de ce travail apostolique ${ }^{37}$.

Durant la même période en Inde, cette nouvelle politique missionnaire trouve autour des années 1570 en la personne d'Alessandro Valignano un exécuteur enthousiaste, dont les héritiers "spirituels" tels que Matteo Ricci et Roberto Nobili allaient pousser la méthode jusqu'à sa limite ontologique, épistémologique et juridique, engendrant pour au moins un siècle et demi des controverses qui aboutiront à «la querelle des rites chinois et malabares" au milieu du XVIII' ${ }^{\circ}$ siècle.

C'est autour de 1558, modestement inscrite dans le texte-mémoire qui nous occupe, mais surtout dans une prodigieuse correspondance jésuite ${ }^{38}$, que s'articule une prise de conscience définitive et irréversible de l'importance de l'apprentissage et de l'enseignement des langues vernaculaires non-européennes. Etroitement liée à la question linguistique, une autre problématique, non seulement absente de notre document, mais presque contradictoire avec les principes fondamentaux de la mission, est celle de la sédentarisation des missions et du personnel missionnaire. D’après $\mathrm{Na}$ dal, "la mobilité apostolique», l'effet direct du quatrième vœu de l'obéissance au pape, était au couur de la vocation jésuite. "Le monde entier est notre maison [totus mundus nostra fit habitatio]», écrit-il dans une exhortation aux jésuites espagnols en $1554^{39}$. Tout en se déplaçant constamment et "en pérégrination", conformément à sa propre prescription, mais sans expérience d'une altérité radicale, il continuait à s'enthousiasmer, comme tout jésuite, de l'utopie d'un monde idéal, sans frontières linguistiques.

Dans les missions asiatiques, en Inde surtout, la réalité était fort différente. Face aux langues difficiles et nombreuses, la première génération des missionnaires jésuites allait signaler que la vision planétaire de Nadal devait être revisée. D’après leur expérience, pour que le travail apostolique puisse faire "fructifier les âmes» des gentils, les missionnaires devaient être affectés à des lieux fixes ou à un territoire linguistiquement homogène. Pour arriver à cette conclusion, virtuelle en 1558 puisque jamais énoncée aussi directement, mais consciemment appliquée dès les années 1570, la période 1542-1558 apparaît comme un espace de transition, vers une pers-

${ }^{37} \mathrm{DI}, \mathrm{X}, \mathrm{p} .830$.

${ }^{38}$ Voir, sur la correspondance missionnaire en général les remarques d'A. Maldavsky, ci-dessous p. 335-337.

${ }^{34}$ Epistolae et monumenta P. Hieronymi Nadal. V. Commentarii de instituto Societatis Iesu, éd. M. Nicolau, Rome, 1962 (MHSI, 90), p. 54; J. W. O’Malley, To Travel to Any Part of the World : Jeronimo Nadal and the Jesuit Vocation, dans Studies in the Spirituality of Jesuits, XVI-2, 1984, p. 6. 
pective hétéroglotte, qui n'était guère moins ambitieuse ou hégémonique que la première dans l'horizon de la conversion religieuse.

Les lettres de François Xavier, dont le comportement apostolique de voyageur inspirait ou confirmait peut-être la prescription de Nadal, montrent pourtant qu'il a privilégié depuis le début la langue portugaise en tant que moyen de communication et de prosélytisme dans les missions asiatiques, sans cependant exclure les langues indigènes si les circonstances l'exigeaient. Le choix du portugais allait de soi, étant donné que missions et missionnaires étaient soumis à l'administration du padroado portugais ${ }^{40}$. À l'époque de sa formation européenne, Xavier, avait, de plus partiellement assimilé les opinions exprimées par João de Barros dans sa Grammatica da lingua portuguesa com os mandamentos da santa madre Igreja (Lisbonne, 1539-40) dont la première partie intitulée Cartinha (un abécédaire combiné avec les principales prières) lui servit de modèle pour son propre catéchisme en portugais et pour ses traductions en tamoul, malais et japonais ${ }^{41}$. D'après Barros, polygraphe humaniste et voyageur immobile, la langue portugaise allait se substituer dans l'avenir à toutes les langues asiatiques. L'empire du portugais et des Portugais, peut-être le cinquième empire dont rêvait Dom Manuel, et peut-être son fils Jean III, est comparé à l'empire romain, dont le déclin était inévitable, mais dont la plus durable conquête avait été la victoire de la langue latine, engendrant à son tour les langues romanes, dont le portugais. Mais, s'il exhortait les missionnaires à apprendre le portugais avant de partir ou durant leur trajet, Xavier ne partageait pas le fantasme de "l'impérialisme linguistique" conçu par Barros. Il se référait à une situation concrète, d'autant que les enclaves marchandes des Portugais en Asie étaient en même temps les centres du rayonnement missionnaire ${ }^{42}$. L'analogie souvent évoquée entre les marchands portugais et les missionnaires, surtout jésuites, désignés comme les «marchands d'âmes», ne contenait aucun sens péjoratif, ni pour les uns ni pour les autres ${ }^{43}$.

${ }^{40}$ F. de Almeida, Histôria da Igreja em Portugal, II, Porto-Lisbonne, 1968, p. 7-46 et 219-221.

${ }^{41}$ João de Barros, Gramática da língua portuguesa; cartinha, gramática, diálogo em louvor da nossa linguagem e diálogo da viciosa vergonha, éd. M. L. Carvalhão Buescu, Lisbonne, 1971; voir aussi M. L. Carvalhão Buescu, A galáxia das linguas na época da Expansão, Lisbonne, 1992; Id., O estudo das linguas exoticas no século XVI, Lisbonne, 1983.

${ }^{42} E X, \mathrm{I}$, p. 293 : «Si de nosa Companñia vieren algunos estrangeros que não saben falar portugues, hé necesario que aprendan a falar, porque de otro jeto não haberá topaz que os entenda".

${ }^{43}$ S. Gonçalves, Primeira parte da história dos religiosos da Companhia de Jesus 
Le portugais, en fait, continuait à servir de lingua franca à l'intérieur des réseaux marchands européens en Asie, même quand les marchands en question n'étaient plus portugais mais, par exemple, hollandais ${ }^{44}$. Néanmoins, la circulation du portugais parmi les divers peuples de l'Asie conduisit nécessairement à la créolisation de la langue. Ainsi, pour les fins de la conversion, Xavier conseille d'adapter le prêche de la doctrine à la langue des néophytes. Avec les esclaves, il faut parler la langue des esclaves, c'est-à-dire "moitié noire moitié portugaise ${ }^{45}$. Ce principe énoncé en 1549 est significatif. On discerne aussi bien un geste d'accommodation linguistique dans son propos, qu'un écho des conceptions de Barros.

Ce qui s'applique aux esclaves portugais ne vaut ni pour les Japonais et les Chinois, admirés par Xavier comme "gens blancs» (gemte bramqua) et "très curieux et désireux des choses nouvelles", ni pour les nouveaux convertis indiens demeurant loin des comptoirs portugais ${ }^{46}$. Après l'expérience linguistique liée à la célèbre mission des années 1542 et 1544 auprès des pêcheurs Paravas, à l'extrême sud de l'Inde, Xavier, incapable d'apprendre la langue tamoule, confie cette tache à ses successeurs ${ }^{47}$. Les ordres de Xavier sont pris à la lettre, la mission de la côte de la Pescaria (ou Pêcherie) ainsi nommée car les Paravas étaient principalement des pêcheurs de perles, fut transformée par des successeurs zélés de Xavier en un véritable laboratoire linguistique. Les missionnaires jésuites - qui furent rarement plus d'une dizaine - installés sur cette côte longue, chaude et sablonneuse, allaient cultiver à leur façon cette "nouvelle vigne du Seigneur» d'une vingtaine de milliers d'âmes au milieu du XVI ${ }^{e}$ siècle.

Le moteur de la mission était Henrique Henriques (1520-1600), qui devait y résider quarante-quatre ans jusqu'à sa mort ${ }^{48}$. Durant sa longue carrière, il allait traduire en tamoul, la langue locale, des textes importants de

[1616], éd. J. Wicki, Coimbra, 1957, vol. I, p. 133 et 137; voir aussi I. G. Zupanov, Prosélytisme et pluralisme religieux : deux expériences missionnaires en Inde aux XVI et XVII' siècles, dans Archives de sciences sociales des religions, 87, 1994, p. 38.

${ }^{44} \mathrm{D}$. Lopes, A expansão da língua portuguesa no Oriente durante os séculos XVI, XVII et XVIII, 2* éd., Lisbonne, 1969; S. R. Dalgado et A. X. Soares, Portuguese Vocables in Asiatic Languages, Baroda, 1936.

${ }^{45} D I$, III, p. 336; $E X$, II, p. 220, 226; DI, I, p. 347.

${ }^{46} E X$, II, p. 9-10; $M J$, II, p. 315. Voir aussi J. S. A. Elisonas, The Jesuits, the Devil, and Pollution in Japan : the Context of a Syllabus of Errors, dans Les portes de l'Asie. Les héritages multiples de Vasco da Gama (à paraître).

${ }^{47}$ Voir G. Schurhammer, Francis Xavier, India, 1541-1545, III, trad., Rome, 1977.

${ }^{4 *}$ Sur Henrique Henriques, né à Vila Viçosa (archidiocèse de Evora), voir J. Wicki, Ein vorbildlicher Missionar Indiens, P. Henriques (1520-1600), dans Studia missionalia [Rome], XIII, 1963. 
l'enseignement de la doctrine chrétienne (deux catéchismes, un manuel de la confession, une vie des saints) ainsi qu'une grammaire du tamoul à l'usage des missionnaires et maints autres textes dont les manuscrits sont aujourd'hui perdus ${ }^{49}$. Son obsession pour la traduction et l'apprentissage des langues indiennes, puisqu'il avait aussi entamé des grammaires du malayalam, du konkani et du telugu, nous semble découler de sa position précaire et ambiguë au sein de la Compagnie due à ses origines de "nouveau chrétien" portugais. Comme il était "condamné" à l'immobilité géographique par crainte d'une trop forte visibilité dans les enclaves portugaises où les accusations de judaïsme devenaient très fréquentes dans la deuxième partie du XVI ${ }^{e}$ siècle, privé des promotions internes accordées aux jésuites de son éducation et de son rang, l'expertise linguistique lui a servi de preuve de l'authenticité de son engagement missionnaire ${ }^{50}$. Sous sa direction, la mission de la Pêcherie devient le premier modèle en Asie d'une mission "vernaculaire», où l'endoctrinement catholique était obligé de se plier à la structure et aux modalités de la langue indigène. Mais la recherche d'une traduction finale et définitive, idéal chimérique, maintenait en fait une certaine instabilité des textes, ouverte aux réparations et aux modifications : Henriques corrige les traductions des prières en tamoul, cautionnées précédemment par Xavier, tandis qu'au début du XVII' siècle un autre jésuite, Roberto Nobili, allait à son tour critiquer et modifier celles de Henriques.

L'importance des langues indigènes pour la réussite missionnaire avait donc été mise en lumière dès l'époque de Xavier, mais ce sont Henriques et ses compagnons de la Pêcherie qui ont porté la question linguistique au premier plan et lui ont accordé une visibilité nouvelle. En particulier, jusque dans les années 1560, leur correspondance avec Rome offre à chaque instant des justifications et des développements concernant les problèmes de l'apprentissage du tamoul. Entre autres arguments pragmatiques, ils affirment que les chrétiens Paravas étaient «très heureux de voir

${ }^{49}$ J. B. Amancio Garcia, Um missionário modelo e linguista. Padre Henrique Henriques de Companhia de Jesus, dans O Oriente português, 3, 1906, p. 252-259; S. X. Thani Nayagam, Tamil Manuscripts in European Libraries, dans Tamil Culture, 3, 1954, p. 219-228, Id., The First Book Printed in Tamil, ibid., 7, 1958, p. 288-308; G. Schurhammer, The First Printing in Indic Characters, dans Id., Gesammelte Studien. II. Orientalia, Rome, 1963 (Bibliotheca Instituti historici Societatis Iesu, 21); et un facsimile de Doctrina Christam (Kollam, 1578) publié dans T. Natan, Tamil moliyin mudal accup puttakam, Celam, 1995.

${ }^{50}$ Voir I. G. Zupanov, Mission linguistique. L'indigénisation du verbe en pays tamoul (XVIe-XVII siècles), dans Archives de sciences sociales des religions, juilletseptembre 1998. 
que nous [les jésuites] étudions leur langue "s", et reprennent par ailleurs l'opinion de Xavier, selon laquelle il fallait surtout éviter les interprètes indigènes (línguas, topaz, etc.), car ceux-ci «mentent», soit parce qu'ils ne comprennent pas bien la doctrine, soit par méchanceté ${ }^{52}$.

Mais la clé de voûte des arguments favorisant l'apprentissage des langues indigènes était la question de l'intériorité de l'autre, dont la géographie toujours inconnue ne pourrait être explorée que par la confession. Les Paravas avaient en outre, dès le début de la mission jésuite, manifesté leur volonté de participer aux scènes de confession dirigées par les missionnaires. À partir de 1549, puis surtout après 1560 , la confession devint un ressort central de la communauté religieuse des Paravas ${ }^{53}$. Les rapports missionnaires de cette époque ne cessent de s'étonner de cette ferveur confessionnelle. Un grand nombre des hommes et des femmes demandait à se confesser quotidiennement, et certains faisaient de véritables pèlerinages pour trouver un prêtre disponible. Cette volonté de tout dire (tous les péchés) était pour les Paravas le moyen de retisser les liens sociaux et de redéfinir des hiérarchies communautaires désarticulées par la conversion. La participation aux sacrements ainsi que le contact rituel et répété avec les prêtres devenait une sorte de mesure de l'honneur individuel et/ou familial ${ }^{54}$.

Pour satisfaire cette demande imprévue, les missionnaires avaient organisé une première école de langue tamoule sur la côte de la Pêcherie à Punikale (Punnaikayal). D’après Henriques, à partir de 1551, les jésuites avaient pris la décision de parler tamoul entre eux, sauf quand ils s'adressaient aux Portugais. Un peu plus tard, ils avaient commencé d'écrire uniquement en tamoul ${ }^{5 .}$. Le manuel de grammaire (Arte) de Henriques, dont un manuscrit est conservé à la Bibliothèque nationale de Lisbonne et qui a connu de nombreuses additions entre 1548 et les années soixante, avait servi de méthode ${ }^{56}$. Calqué sur la grammaire latine, l'Arte da língua Malabar était à la fois un instrument extraordinaire pour l'apprentissage analytique de la langue et une description relativement exacte de la morphologie, de la syntaxe et phonétique tamoules. Le succès de sa méthode avait persuadé Henriques qu'en procédant à l'identification des déclinaisons et des conju-

" $D I$, I, p. 582.

${ }^{52} \mathrm{DI}, \mathrm{II}, \mathrm{p} .158$.

${ }^{5.3} \mathrm{DI}, \mathrm{I}, \mathrm{p} .582$.

${ }^{\$ 4}$ Voir I. G. Zupanov, Prosélytisme... cit.

${ }^{55} \mathrm{DI}, \mathrm{II}, \mathrm{p} .159$.

"th Voir l'édition imprimée dans H. J. Vermeer, The First European Tamil Grammar, Heidelberg, 1982; J. H. Hein, Father Henriques' Grammar of Spoken Tamil, dans Indian Church History Review, 11, 1977, p. 127-157. 
gaisons, il serait capable de rédiger très rapidement les grammaires des autres langues non-européennes. D'après ces lettres, c'est exactement ce travail qu'il entreprend après 1565. C'était aussi sa manière de voyager, d'entreprendre un apostolat mobile tout en restant sur place, et de réduire la tension entre le principe du déplacement, les exigences de l'apprentissage et les contraintes spécifiques liés à son statut de nouveau-chrétien.

Un autre jésuite, Nicolao Lancillotto, qui circule dans les diverses enclaves portugaises en Inde sans jamais s'y installer plus d'un an, n'a pu apprendre aucune langue indigène. Pour cette raison, en 1552, il demande à Ignace de Loyola d' "ordonner (mandar)» que les "pères qui viennent ici, aient des provinces bien déterminées (provincias certes) pour pouvoir apprendre les langues parce que par les interprètes", ajoutait-il, "on fait très peu de fruit ${ }^{57}$. Cautionnant ainsi la stratégie missionnaire des jésuites de la côte de la Pêcherie, il en avait en réalité adopté une autre en éduquant un jeune garçon pour en faire son propre interprète, un brahmane, Pedro Luis, qui allait devenir jésuite en 1560 , le seul jésuite indien du XVI siècle.

Dans sa réponse, Ignace de Loyola approuve toutes les suggestions de Lancillotto, en particulier celle sur les provinces "fixes» (provincias firmes) pour stimuler l'apprentissage des langues. Comme on l'a noté, le document de 1558 ne propose pas explicitement cette disposition, qui nous semble pourtant importante, pour la discussion lors de la première congrégation de l'ordre. L'ouverture linguistique, une sorte de second miracle de Pentecôte ${ }^{58}$ était aussi inscrite dans les Constitutions de l'ordre. Loyola prévoit ainsi dans les collèges des professeurs "d'autres langues comme l'hébreu, le chaldéen, l'arabe et l'indien" (outre l'enseignement du grec et du latin) ${ }^{59}$. Mais les prescriptions des Constitutions étaient toujours facultatives. Il faut ajouter aussi que la congrégation de 1558 opère une «autre ligne de partage, entre les langues 'dans lesquelles fut écrite ou traduite l'Écriture' et celle qui lui restent étrangères " ${ }^{60}$. Les langues non-européennes ne furent pas prioritaires avant 1558 dans l'enseignement jésuite des collèges européens. L'apprentissage de l'arabe commence en 1555 à Messine, et au Collège romain en 1565, tandis qu'Henriques, dans une périphérie missionnaire lointaine, rêve d'un «vrai» collège pour les Paravas, en tamoul.

Mais une rumeur provenant de Goa, prépare la future légende noire de la présence jésuite au Portugal. Les missions "vernaculaires» en Inde seront bientôt accusées d'être anti-portugaises. De plus, les jésuites seront

${ }^{57} \mathrm{DI}, \mathrm{III}, \mathrm{p} .381$.

${ }^{58}$ Voir également ci-dessous les remarques de Charlotte de Castelnau.

${ }^{59}$ Ignace de Loyola, Écrits cit., p. 482-3, 502-3

${ }^{60}$ Ibid., p. 502. 
coupables, d'après cette accusation, de ne pas vouloir enseigner le portugais aux néophytes et de vouloir s'imposer eux-mêmes en tant que médiateurs (les línguas, les truchements) entre les Indiens et les Européens.

En 1558, d'après le témoignage de notre document, les décisions institutionnelles sur l'apprentissage des langues indigènes n'étaient pas encore prises, et les difficultés que nous venons d'évoquer, virtuellement contenues dans le choix de l'apprentissage, ne sont peut-être pas étrangères à cette prudence; mais l'expérience des jésuites œuvrant dans les missions non-européennes allait pourtant bientôt éliminer les doutes sur la nécessité de cette ouverture linguistique (I. G. Z.).

\section{Recrutement et formation des missionnaires}

La langue, baromètre de la mission

En lui consacrant un paragraphe entier, le texte de 1558 marque le début d'une évolution sur la question de l'apprentissage des langues indigènes :

Il faudrait aussi que les nôtres envoyés depuis l'Europe apprennent les langues de cette sorte de nations, et qu'ils soient aidés pour cela par la grammaire et par l'usage, si vraiment on juge qu'ils ont des dispositions pour cela ${ }^{61}$.

L'apprentissage de la langue locale apparaît cependant ici comme une composante utile parmi d'autres pour ceux qui quittent l'Europe en direction des terres de mission, et réservée à quelques-uns seulement. On retrouve là l'esprit des Constitutions qui évoquent la question de l'apprentissage des langues dans la IV ${ }^{\text {e }}$ partie qui concerne "la formation dans les lettres»:

Quand dans un collège ou une université, on formerait le projet de préparer certains sujets pour aller chez les Maures ou les Turcs, l'arabe ou le chaldéen seront indiqués; ou l'indien, pour aller aux Indes; et ainsi des autres langues, qui pourraient être plus utiles en d'autres pays pour des raisons semblables ${ }^{62}$.

${ }^{61}$ "Ut nostri linguas addiscant: Nostros etiam ex Europa missos, linguas addiscere huiusmodi nationum oporteret, et arte ac usu ad id juvari, si quidem indole ad id praediti censerentur».

${ }^{\circ 2}$ Constitutions [449], dans Ignace de Loyola, Écrits cit., p. 502. 
La question linguistique y est abordée de façon très pragmatique : toutes les langues sont bonnes à apprendre pourvu qu'elles soient utiles. On remarque dans ce domaine linguistique pourtant complexe, la même simplicité qui prévaut lorsque les Constitutions abordent par exemple la question du vêtement : «le vêtement doit être adapté aux usages du pays où l'on vit ${ }^{63}$. Selon ce principe d'adaptation et puisque l'usage de la langue du pays est utile aux missionnaires, son apprentissage est recommandé aux pères.

Quarante ans plus tard, la congrégation générale de 1594 insiste au contraire sur le fait que tous ceux qui sont aux Indes doivent connaître les langues indiennes. Le décret n'évoque plus un apprentissage utile mais "très nécessaire» car, poursuit-il de façon emphatique, "la connaissance des langues est le moyen d'atteindre le salut des Indiens, or le salut des Indiens est l'unique raison ou la principale de la présence des jésuites dans ces terres ${ }^{64}$.

L'évolution est très nette : l'apprentissage des langues concerne désormais tous les jésuites des provinces d'outremer, il est au cœur du projet missionnaire, et teinté d'une forte coloration religieuse. Comment expliquer l'évolution entre le texte de 1558 et celui de la congrégation générale de 1594? Que signifie-t-elle concrètement pour l'apprentissage des langues?

La langue et la vocation missionnaire

\section{De l'utilité à la nécessité}

L'idée que l'apprentissage des langues indigènes est nécessaire pour tous les jésuites des provinces d'outre-mer est le fruit des expériences menées sur les terres de mission. Dès leur arrivée sur les terres de mission, les jésuites estiment que le contact avec les indigènes ne peut s'établir que dans leurs langues. La langue indigène devient l'instrument de l'apostolat vis-à-vis des Indiens. Les missionnaires connaissant les langues indigènes sont indispensables; ce sont les seuls à pouvoir clairement assumer la vocation missionnaire de la Compagnie.

Les provinces missionnaires écrivent à Rome pour dire qu'elles ont un besoin extrême de prêtres linguistes. Ainsi en 1568 au Brésil, le besoin de prêtres pour confesser les Indiens est tel que la connaissance de la langue indienne devient un critère essentiel pour le recrutement des jeunes jé-

${ }^{63}$ Constitutions [577], ibid., p. 535.

${ }^{64}$ Ce décret est publié par A. Padberg et al., op. cit., p 211 (Ve congrégation, décret 66). Dans la numérotation de 1594, c'est le décret 85. 
suites; la congrégation provinciale demande ni plus ni moins à Rome que l'ordination et la profession soient conférées à ceux qui connaissent la langue indienne même "s'ils ne savent pas le latin" et même s'ils ont "peu de sciences et d'arts ${ }^{65}$. Ainsi, la maîtrise de la langue indienne est à ce point indispensable que l'on est prêt à négliger les étapes normales de la formation.

Lorsque la Compagnie doit réaffirmer sa présence ou son rôle dans la société coloniale, elle le fait au nom de sa vocation missionnaire, symbolisée par le fait que les jésuites connaissent les langues indigènes. Ainsi en 1592, la congrégation brésilienne demande une dispense pontificale pour que les jésuites puissent confirmer les néophytes «car les nôtres sont les seuls à comprendre les Indiens" "th. La dispense ne sera pas accordée mais cette demande montre comment la connaissance des langues devient un argument pour revendiquer un monopole missionnaire. Selon la congrégation, la connaissance de la langue implique pour les jésuites une spécialisation missionnaire et des privilèges particuliers. La connaissance des langues indigènes est donc de plus en plus clairement un élément essentiel de l'identité missionnaire, un élément "très nécessaire" selon le décret de la congrégation générale de 1594. Au moment où il devient obligatoire, cet apprentissage se charge désormais d'une nouvelle signification spirituelle.

\section{La voie du salut pour l'indien et pour le missionnaire}

En apprenant des langues nouvelles, le missionnaire devient l'héritier direct des apôtres recevant le don de glossolalie le jour de la Pentecôte pour annoncer le Christ aux peuples du monde victimes de la diversité linguistique depuis Babel. Le thème biblique apparaît constamment dans les ouvrages de missiologie et particulièrement chez José de Acosta dans le De procuranda Indorum salute. Cependant les jésuites à la différence des apôtres n'ont pas tous reçu de l'Esprit Saint le don des langues et il leur faut passer par un difficile apprentissage linguistique. Dans une lettre magnifique de 1577 adressée aux jésuites des Indes occidentales et orientales, le général Mercurian fait de cet apprentissage une grâce divine ${ }^{67}$. Il le décrit en deux temps : d'abord détachement de soi puis mouvement vers les Indiens. Apprendre la langue des Indiens c'est leur témoigner de la sympathie

"5 "Postulados da primeira congregação provincial do Brasil (1568)», § 7 et 8 (MB, IV, p. 467).

to Cette supériorité linguistique des jésuites au Brésil sur le reste du clergé tient notamment au fait qu'ils ont été le premier ordre religieux de la colonie.

67 Il existe plusieurs versions de cette lettre, adressée à toutes les provinces d'outre-mer (voir en particulier MP, II, doc. 39, p. 313-317, et ci-dessus note 35). 
au sens fort, c'est les comprendre, les aimer et se faire aimer d'eux. L'apprentissage de la langue est décrit ici comme un exercice spirituel, préfigurant le cheminement de l'âme du missionnaire lors de l'apostolat.

Le décret de 1594 qui officialise l'importance de l'apprentissage des langues indigènes insiste clairement sur la valeur spirituelle de leur connaissance : c'est elle qui permet $d^{\prime}$ '«atteindre le salut des peuples de l'Inde». Les langues indigènes ne sont plus appréhendées d'un simple point de vue pragmatique (du point de vue de l'utilité pour l'apostolat) comme dans le texte de 1558 mais elles représentent désormais un élément essentiel dans l'économie du salut qui se joue entre missionnaire et missionné (le missionnaire est celui qui fait son salut en faisant celui des autres). Entre les premières expériences missionnaires et la fin du XVI ${ }^{e}$ siècle, il y a donc eu une remarquable évolution de la position de la hiérarchie centrale vis-à-vis de la question linguistique missionnaire : pour Rome, la connaissance des langues indigènes est devenu désormais l'attribut essentiel du missionnaire. Comment s'organise l'apprentissage sur le terrain?

L'apprentissage linguistique, par les livres et par l'usage

Le $\$ 18$ du texte de 1558 évoque deux méthodes d'apprentissage : par la grammaire et par l'usage. En 1575-77, probablement en réponse à une même question envoyée par Rome, les congrégations provinciales du Brésil, du Pérou et du Mexique apportent des précisions sur cet apprentissage $^{68}$. Dans chacune de ces provinces, les langues locales s'apprennent soit par l'expérience sur le terrain, en vivant parmi les Indiens, soit d'une façon plus théorique, dans les collèges au moyen de livres. Mais selon les situations, on accorde plus ou moins d'importance à l'une ou l'autre de ses méthodes; ces variations révèlent le statut différent que peuvent avoir les langues indigènes.

Au Brésil, il est clairement dit que la langue ne s'apprend correctement que parmi les Indiens, d'ailleurs les pères ont fermé en 1574 le cours de tupi du collège de la Bahia car l'apprentissage théorique ne donnait aucun résultat. Les jésuites du Pérou estiment que si les rudiments peuvent s'apprendre dans les collèges, il faut néanmoins se perfectionner sur le terrain, en accompagnant des missions. Ils évoquent aussi, de même que les pères du Mexique, l'existence de chaires de langues indigènes à l'université (quechua et aymara à Lima et nahuatl à Mexico) occupées par des membres des autres ordres religieux, sous-entendant une forme de concurrence linguis-

${ }^{68}$ Actes de la congrégation provinciale (noté C.P.) du Brésil, 1575, § 1 (ARSI, Cong. 42, fol. 321r-322r), Actes de la C.P. du Pérou, 1576, § 20 (MP, II, doc. 17, p. 68), Actes de la C.P. du Mexique, 1577, § 30 (MM, I, doc. 112, p. 323-324). 
tique entre les différents ordres ${ }^{69}$. Au Pérou et au Mexique, l'apprentissage des langues indigènes représente clairement un enjeu intellectuel qu'il n'a pas au Brésil où le tupi reste une langue orale.

La comparaison entre les provinces montre la diversité des situations linguistiques et les efforts d'adaptation des jésuites pour organiser de la manière la plus efficace cet apprentissage linguistique.

\section{Les difficultés du terrain}

Toutes les provinces reconnaissent que pour parler correctement la langue, il faut l'avoir apprise parmi les Indiens. Il faut donc organiser les modalités de cette insertion des jésuites en milieu indien. Le cas du Brésil est révélateur car il a toujours privilégié le «terrain» au détriment de l'apprentissage théorique et du fait de la précocité de l'arrivée des jésuites (1549), il a été le lieu des expérimentations. Les jésuites du Brésil ont ainsi envoyé les enfants portugais de leurs écoles dans les villages indiens pour apprendre le tupi dans l'espoir que cette langue leur deviendrait familière dès le plus jeune âge, en quelque sorte une langue vernaculaire. La congrégation provinciale de 1568 veut mettre fin à cette expérience car, dit-elle, les enfants de moins de 14 ans ayant vécu parmi les Indiens, se révèlent ensuite inadaptés à la discipline jésuite et incapables d'entrer dans la Compagnie; ces écoles ne remplissent alors plus leur rôle qui est d'être des viviers de recrutement pour la province ${ }^{70}$. Selon les pères de la congrégation, ces enfants sont «imbibés» par les mœurs indiennes, c'est-à-dire imprégnés comme des éponges : cette expression remarquable équivaut à un constat sans équivoque de l'attraction du modèle indien auquel les jeunes enfants ne sauraient résister.

Le cas brésilien est certes paroxystique - puisqu'il s'agit de jeunes enfants - mais il en est pas moins révélateur du risque que la vie en milieu indien fait courir à tout jésuite, risque d'autant plus grand qu'il est jeune et peu formé. Ce risque est constamment évoqué et il explique que l'on prenne de plus en plus de précautions pour ce que l'on peut appeler les «séjours linguistiques» en milieu indien.

${ }^{69} \mathrm{Au}$ Mexique et au Pérou, les ordres mendiants étaient devenus, bien avant les jésuites, experts dans la connaissance des langues indigènes. Au Mexique, les franciscains ont accompli une remarquable œuvre linguistique, créant notamment une littérature coloniale nahuatl. Au Pérou les dominicains ont été également des spécialistes de la langue quechua.

70 "Postulados da primeira congregação provincial do Brasil (1568)», § 2, MB, IV, p. 465. 
Du séjour linguistique à l'expérience missionnaire

L'âge où on effectue ce séjour linguistique est alors repoussé : on envoie dans les missions ou dans les villages indiens, non plus les écoliers mais les jeunes jésuites après leur entrée au noviciat. Ces jeunes gens plus âgés et plus formés sauront mieux résister aux tentations de la vie indienne. Le séjour parmi les Indiens devient dans ce nouveau cadre une première expérience de vie missionnaire. Dans le parcours de formation que suit tout jésuite, l'expérience linguistique est assimilée à une de ces épreuves (probations) que le novice doit faire avant d'entrer définitivement dans la vie religieuse. L'apprentissage des langues permet au jésuite en formation d'expérimenter en grandeur nature la vie de missionnaire.

L'apprentissage des langues n'est plus simplement une formation intellectuelle (ainsi que les Constitutions l'envisageaient) mais il devient également une étape de la formation religieuse. Cette ambiguïté de statut se retrouve dans les multiples débats qui portent sur le choix du moment de cet apprentissage au cours des études, comme celui qui a lieu lors de la congrégation provinciale du Mexique en 1585 : faut-il apprendre la langue locale avant la philosophie, entre la philosophie et théologie ou juste avant le sacerdoce? ${ }^{71}$ Ainsi, pour protéger les jeunes jésuites des dangers inhérents à "l'usage» de la langue - dangers provoqués par le contact durable avec les Indiens - le "séjour linguistique» se transforme en expérience missionnaire. Parallèlement à cet apprentissage par l'expérience se développent des instruments pédagogiques pour un apprentissage plus théorique, par les livres.

\section{«L'art de la langue»}

Le $\S 18$ évoque les arts de la langue pour aider les missionnaires dans leur apprentissage linguistique ${ }^{72}$. En effet, les grammaires des langues indigènes qui les "réduisent " aux règles de la grammaire latine ont une dimension pédagogique et doivent servir de manuels à l'usage des missionnaires. Au fur et à mesure que l'apprentissage des langues se généralise, les différentes provinces demandent l'impression des livres en langues indigènes, qui permet une meilleure diffusion. Le cas du Brésil est révélateur de ce

${ }^{7}$ Actes de la C.P. du Mexique, 1585, § 25-26 (MM, II, doc. 200, p. 637).

${ }^{72}$ On s'intéressera exclusivement ici à la dimension pédagogique de ces arts de la langue présente dans le texte de 1558. Pour une analyse plus générale du cas brésilien, voir Andréa Daher, ci-dessous. Sur les aspects liés à la dimension cognitive de la mission, voir C. de Castelnau-L'Estoile, Entre curiosité et édification : le savoir des missionnaires jésuites du Brésil, dans Sciences et religions de Copernic à Galilée, Rome, 1999 (Collection de l'École française de Rome), à paraître. 
lien car ce n'est qu'en 1595, un an après le décret sur l'apprentissage obligatoire des langues, que la hiérarchie romaine ordonne l'impression de la grammaire tupi d'Anchieta alors que la province en a fait la demande dès 1575 et que la grammaire circule sous forme manuscrite depuis les années $1560^{73}$.

Le texte de 1558 n'évoque pas les catéchismes, mais les congrégations provinciales postérieures mettent en général grammaires et catéchismes sur le même plan lorsqu'elles demandent l'impression d'ouvrages en langue indigène. Ces deux types de livres sont deux instrument pédagogiques, l'un destiné aux Indiens pour apprendre les rudiments de la foi chrétienne et l'autre destiné aux jésuites pour apprendre la langue indienne. Cependant le catéchisme est lui-même conçu comme une méthode de langue pour les jésuites. En effet, il existe un premier niveau de connaissance des langues indigènes, requis pour tous à partir des années 1580 , qui reste strictement limité aux besoins de l'apostolat (sermons stéréotypés, confessions). Ce premier niveau peut s'acquérir dans les catéchismes qui donnent une version bilingue des principaux textes de la Doctrine (les cinq grandes prières, le credo et l'explication des commandements et sacrements).

Les enjeux autour de l'apprentissage des langues indigènes

La connaissance des langues indigènes étant devenu l'attribut essentiel du missionnaire, la question de leur apprentissage dépasse les enjeux purement linguistiques. Les débats qui divisent les provinces ou qui existent entre Rome et les périphéries sur les questions de langue sont souvent les formes euphémisées dont on enveloppe des questions plus essentielles touchant la vocation missionnaire des provinces. Que signifie ainsi le refus d'apprendre la langue indienne? En effet, malgré les injonctions répétées de Rome, malgré l'importance religieuse que la hiérarchie donne à cet apprentissage, les textes font état de nombreuses résistances du personnel jésuite pour apprendre les langues indiennes. Dès 1575 au Brésil, on perçoit cette résistance. Les pères de la congrégation provinciale tentent de faire approuver par Rome l'emploi des coadjuteurs temporels dans l'apostolat auprès des Indiens alors que les coadjuteurs temporels sont théoriquement confinés dans les tâches strictement matérielles. Les pères justifient ce

${ }^{73}$ Voir Pero Rodrigues, Da vida do Padre José de Anchieta, da Companhia de Jesus, Quinto Provincial que foi da mesma Companhia no Estado do Brasil, dans Primeiras biografias de José de Anchieta, éd. H. Viotti, São Paulo, 1988, p. 63-64. 
manquement aux règles de l'institution «à cause de la connaissance de la langue indienne ${ }^{74}$.

La langue indienne apparaît utilisée ici comme prétexte et le véritable enjeu semble bien le fait de vouloir confier l'apostolat des Indiens aux jésuites subalternes. Rome refuse très nettement et rappelle dans sa réponse les règles de l'institut concernant les coadjuteurs temporels, preuve sans doute que la hiérarchie a lu entre les lignes de cette demande et qu'elle y a vu un danger pour l'institution. Aussi les questions de langue convoquentelles rapidement - mais indirectement - des enjeux plus importants qui concernent la vocation missionnaire en tant que telle. Mais si apprendre la langue indigène c'est risquer de devenir missionnaire, alors tous ceux qui ne désirent pas être missionnaires risquent de refuser de l'apprendre.

Or à partir des années 1580 on perçoit, en effet, une résistance de la part des scolastiques, c'est-à-dire des étudiants déjà entrés dans la Compagnie. Ils écrivent à Rome pour dire que l'apprentissage des langues locales alourdit leur cursus d'études et leur fait perdre du temps. Cela signifie sans doute que, contrairement à ce que Rome veut entendre, la mission n'est plus l'unique objectif des jésuites des provinces d'outre-mer et que la carrière missionnaire symbolisée par cet apprentissage linguistique, n'attire pas tous les jésuites. Ces hypothèses, fournies par une lecture attentive de ces débats autour de la langue, demanderaient à être confirmées par d'autres analyses, notamment par l'analyse de la carrière missionnaire à partir d'études prosopographiques ${ }^{75}$. L'attitude de Rome reste ferme vis-àvis de ces formes de résistances : la réponse romaine est de faire un chantage au sacerdoce : personne ne pourra être ordonné dans ces régions sans connaître les langues indigènes. Face à cette fermeté, les provinces ne cessent de demander des exceptions - preuve, sans doute, que sur place on ne respecte pas les ordres de la lointaine hiérarchie.

Le texte de 1558 signale déjà la maîtrise des langues indigènes comme la différence fondamentale entre les missionnaires locaux et les autres, auxquels l'apprentissage de ces langues indigènes est conseillé. Mais il ne

${ }^{74}$ C.P. du Brésil, 1575, $\$ 10$ (ARSI, Cong. 42, fol. 321r-322r) et Réponses [de Rome] (ARSI, Cong. 93, fol. 205-207)

${ }^{75}$ Le Groupe de recherches sur les missions ibériques modernes s'est engagé dans la constitution d'une prosopographie du personnel missionnaire dans l'ensemble des terres de mission en zone ibérique pour les années 1570-1580 et 16201630 , afin de mesurer l'évolution des profils de carrière entre ces deux périodes, marquées la première par la réunion des couronnes d'Espagne et du Portugal et une expansion considérable du nombre des missionnaires, la seconde par l'ouverture d'une nouvelle époque de l'histoire des missions avec la création de la Propaganda Fide romaine. 
prend pas encore toute la mesure de cette distinction, pour ce qui concerne la formation des missionnaires européens et la nécessité d'un recrutement local : la connaissance des langues indigènes n'est qu'un aspect de la politique missionnaire de la Compagnie, et son apprentissage ne semble pas a priori poser de problèmes particuliers.

L'expérience de terrain, rapportée en filigrane par les actes des congrégations provinciales, a renforcé progressivement ensuite l'idée de l'importance des langues locales, et a fait apparaître les difficultés de cet apprentissage nécessaire. Dans les années 1580 , la hiérarchie romaine décide de le rendre obligatoire : la connaissance ou la capacité d'assimiler les langues indigènes devient synonyme d'une vocation missionnaire. Du coup, les débats autour de l'apprentissage de la langue locale prennent de plus en plus d'importance et recouvrent en réalité des enjeux plus fondamentaux, au premier rang desquels la possibilité d'un relais missionnaire au sein même des provinces d'outre-mer.

Sur la question des langues comme sur beaucoup d'autres, le texte de 1558 esquisse un bilan tout en proposant des axes de réflexion définis en fonction d'une expérience acquise en Asie et au Brésil. Sur fond de pénurie structurelle, l'apprentissage des langues locales, déjà posé par les Constitutions, devient l'une des données qui structurent le recrutement et la formation des missionnaires, et le pivot d'un échange de compétences à travers lequel se dessine une géographie des talents (C. d. C.).

\section{Une géographie des talents}

La sélection des individus qui devront se consacrer à la moisson des âmes en terre de mission trouve une subtile formulation dans le $\S 3 \mathrm{du}$ texte de 1558, intitulé : «De l'envoi d"ouvriers' aux Indes». En répondant à la question : qui doit partir?, il laisse sur sa faim le lecteur à l'affût d'un portrait du missionnaire idéal. Aucune liste de qualités ne vient détailler «la capacité d'accomplir cette tâche», qui constitue l'un des critères de sélection. Mais des choix sont proposés entre les différentes catégories d'individus appartenant à la Compagnie, qui contribuent à dessiner un portrait du missionnaire, en fonction non seulement de ses qualités propres, mais aussi de critères relatifs à la gestion de l'ensemble des membres de l'ordre.

Des missionnaires formés et parfaits

Les «ouvriers» dont le texte de 1558 prévoit l'envoi aux Indes sont en priorité des profès. Le $\S 3$ ne les nomme pas précisément, mais il formule l'alternative suivante. Après avoir énuméré des critères de sélection (volontariat, capacités personnelles, économie de la circulation des jésuites), il 
établit une hiérarchie entre les membres de la Compagnie. Évoquant «les coadjuteurs en formation ou les élèves", il indique que les membres encore partiellement formés ne doivent pas être choisis en priorité. Le principal critère de sélection des futurs missionnaires consiste dans l'accomplissement de leur formation. Il n'est donc pas nécessaire de formuler précisément les qualités requises, et seuls les jésuites en cours de formation se voient attribuer des caractéristiques plus détaillées : «on choisira ceux qui ont été dotés d'un talent moindre dans les lettres, mais de grandes vertus morales".

Si la qualité essentielle du futur "ouvrier" en terre de mission est d'être profès, son portrait est cependant affiné par le couple : talent dans les lettres et vertus morales, mininum exigé du jésuite accompli. Le chapitre 2 de la cinquième partie des Constitutions indique "les qualités requises pour être admis» à la profession. Outre le succès dans les études, et donc les capacités intellectuelles, le futur profès doit faire preuve de vertus religieuses, comme l'humilité, l'abnégation, l'amour de Dieu. Et si la réunion du talent et des vertus n'est pas parfaite, le futur missionnaire doit faire ses preuves sur les deux fronts pour être admis à formuler ses vœux ${ }^{76}$. Le profès personnifie la perfection au sens littéral d'un achèvement et d'une complétude. L'imprécision du texte de 1558 sur le sujet des qualités intellectuelles des futurs missionnaires confirme l'idée que tous les membres formés de la Compagnie doivent être à même d'assurer les ministères pris en charge par l'ordre, quel que soit le lieu géographique de cet exercice.

\section{Des qualités supplémentaires}

Ce portrait fait écho à une requête du provincial de l'Inde qui, en 1557, demandait à Ignace de ne pas envoyer de sujets "imparfaits" (imperfeitos) ${ }^{77}$. Il répond aussi à Manuel da Nóbrega qui, en 1555, accusait le Portugal d'envoyer au Brésil les moins qualifiés de ses membres tout en insistant sur l'ampleur des qualités requises : "nulle part ailleurs sont aussi nécessaires la prudence, la force, la science, l'intelligence et toutes les autres vertus, comme ici pour la conversion des infidèles ${ }^{78}$. Cette perfection semble

${ }^{76}$ Constitutions [518], dans Ignace de Loyola, Écrits cit., p. 519. p. 611).

${ }^{77}$ G. da Silveira à Ignace de Loyola, Cochin, 10-27 (?) janvier 1557, § 2 (DI, III,

${ }^{78}$ «En ningunas partes son tan necessarias la prudentia, fortaleza, scientia, spiritu y todas las otras virtudes como aquá para el negocio de la conversión de los infieles" (lettre du P. Manuel da Nóbrega à Ignace de Loyola, São Vicente, 25 mars $1555, \S 6, M B, \mathrm{II}$, doc. 31 , p. 168). 
pourtant difficile à atteindre : en 1566, peut-être pour se justifier de ne pas proposer des sujets pour les missions, le provincial du Portugal écrit à François de Borgia que "si l'on considère les qualités que le provincial d'Inde demande de ceux qui doivent aller là-bas, je ne vois personne dans cette province qui les réunisse ${ }^{79}$. Le témoignage et les exigences des Provinciaux semblent contredire le modèle proposé par le texte de 1558 , la conversion des infidèles apparaissant pourtant sous la plume de certains d'entre eux comme une tâche à part, et comme la spécificité des terres de mission. Le texte romain, en revanche, insiste seulement sur les «vertus morales» qui, pour les individus en formation, constitueraient le trait distinctif des terres de missions par rapport aux autres lieux. En décembre 1558, le P. Laínez écrivait aux jésuites d'Inde : «ceux qui êtes làs-bas avez la grande obligation de posséder la perfection dans les vraies et solides vertus» ${ }^{80}$. La différence entre «ici» et "là-bas» réside davantage, pour Rome, dans les risques encourus par les jésuites eux-mêmes quant à leur propre salut que dans la nature de leur tâche. Le futur missionnaire, quel qu'il soit, doit être particulièrement vertueux, étant donnés les dangers auxquels des pérégrinations solitaires pourraient exposer son vœu de chasteté. Ainsi, par exemple, l'aptitude à la maîtrise des langues n'agit-elle pas dès le début comme un critère de sélection, puisque les jésuites envoyés d'Europe ne doivent les apprendre que «si vraiment ils ont des dispositions pour cela» $(\S 18)^{81}$.

\section{Entre volonté des individus et gestion du personnel}

Dans ces conditions, le principal critère de sélection de ces «ouvriers» particuliers réside dans l'appel intérieur "pour une mission de ce genre», qui doit pouvoir être vérifiée par les supérieurs. Laínez insistait sur les nécessaires «inclinations et désirs spirituels» qui doivent animer les futurs missionnaires ${ }^{82}$. L'impératif de disponiblité contenu dans le quatrième vœu

79 "Si se consideran las partes que el P. Antonio de Quadros pide en los que an de ir a aquellas partes, yo cierto que no veo ninguno en esta provincia, porque no se pueden hallar tantas y tales juntas en un sujeto" (lettre du P. Leo Henriques, provincial du Portugal, au général Borgia, 30 juillet 1566, § 1, DI, IV, doc. 7, p. 13).

${ }^{80}$ "Los que alla estays teneys grande obligacion de procurar toda perfeccion en las verdaderas y solidas virtudes" (Rome, $1^{\text {er }}$ décembre 1558, DI, IV, p. 110).

${ }^{81}$ La réalité prend toutefois le dessus sur l'énoncé des principes, par exemple en 1576, les jésuites de Lima demandent à Rome l'envoi d'Italiens, car ils ont constaté qu'ils apprenaient mieux que les autres les langues locales (lettre des P. Plaza, Acosta et Piñas au général Mercurian, Cuzco, 12 décembre 1576, § 3, MP, II, p. 104).

${ }^{2} 2$ "Chi habbia inclinationi et spirituali desiderii" (Lettre aux supérieurs de la Compagnic, Rome, 19 décembre 1558, LM, IV, doc. 1066, p. 76). 
avec l'obligation d'obéissance ne semblent pas suffire. Comme l'entrée dans la Compagnie ${ }^{83}$, le départ en mission doit être le fruit de la volonté de l'individu, le supérieur devant avoir une «pleine connaissance des inclinations et des motions des individus dont il a la charge», pour prendre la décision qui convient ${ }^{84}$. Le document de 1558 annonce les Indipetae, littéralement lettres de "demande des Indes», que les membres de la Compagnie écrivaient au général pour proposer leur services en terre de mission, et dont on trouve trace en Espagne dès la fin des années $1570^{85}$.

La sélection semble s'être appuyée en priorité sur ce volontariat, mais le choix est en dernière instance déterminé par des critères extérieurs aux individus, qui intéressent toute la Compagnie dans la gestion de son personnel, puisque «doivent être choisis ceux qui pourront être envoyés sans préjudice grave pour les régions proches et pour le profit des régions lointaines» (§ 3). Malgré le balancement géographique, qui fait apparaître une distinction entre «ici » et "là-bas", le texte se garde de préciser le cadre définitif des choix, préservant la plus complète imprécision et la plus ample ouverture vis-à-vis des supérieurs chargés de la sélection, auxquels il laisse le choix de refuser de se séparer de leurs précieuses recrues.

La conscience de la spécificité des terres de missions, sanctionnée par l'existence même de notre document, est en permanence oblitérée par l'exigence de cohérence et d'unité dans la Compagnie que déterminent d'une part la perfection du personnel sélectionné et d'autre part l'équilibre nécessaire entre toutes les régions (A. M.).

\section{La question du clergé indigène}

Il paraît logique, même si les documents sont peu bavards à ce sujet, que, sur leurs divers terrains, les missionnaires, jésuites ou autres, aient été aidés par des autochtones. Ces derniers ont fait office de guides, de traducteurs, voire de protecteurs. Poser la question de l'émergence d'un «clergé indigène» fait cependant franchir un grand pas, chronologique et mental. A priori cette question devrait se situer à l'interface des questions de per-

${ }^{83}$ Constitutions [50], dans Ignace de Loyola, Écrits cit., p. 405.

${ }^{84}$ Constitutions [92], ibid., p. 414.

${ }^{85}$ Les Indipetae (14000 lettres conservées pour la période 1580-1770) constituent une source extrêmement précieuse, et peu exploitée, pour l'étude des motivations de l'«individu» missionnaire, de la hiérarchisation des terres de mission ( par rapport à l'expression de ces motivations), et du décalage entre les demandes individuelles de mission et les envois effectifs. Le Groupe de recherches sur les missions ibériques modernes poursuit actuellement une enquête méthodique sur les Indipetae rédigées en Espagne, au Portugal et en Italie entre la fin des années 1570 et les premières années du XVII ${ }^{e}$ siècle. 
sonnel missionnaire et des rapports qu'entretient ce dernier avec le terrain indigène. En réalité, elle relève du domaine de l'indicible ou du moins une pensée théorique lui fait longtemps défaut.

En effet, dans notre corpus, l'expression "clergé indigène» n'apparaît nulle part dans les années 1550 et 1560 . Il est fait mention d'hommes utiles au service divin, d'hommes pouvant aider la Compagnie, mais l'idée d'un clergé composé de natifs n'est pas formulée comme telle. Les textes, particulièrement concis, font alterner un "acá», l' «ici » de l'Europe, de Rome ou du Portugal et un «allá», le "là-bas» des missions. Ils opposent les "hombres de acá» que l'on envoie en mission s'ils présentent les caractéristiques morales et intellectuelles suffisantes et les "hombres de allá " que l'on recrutera avec d'autant plus d'exigence qu'ils sont "issus de l'infidélité». Des "hommes aptes», pourront, entre autres à ce titre, entrer dans la Compagnie mais l'idée même d'un clergé composé de natifs n'est énoncée qu'en 1577 : la congrégation provinciale du Mexique propose la création d'un corps de jésuites indiens, et ce, à destination exclusive des Indiens païens ${ }^{86}$. Le moins que l'on puisse dire est que cette idée est malaisée à penser. Comment accepter en effet que les "troupes d'élite» que sont les jésuites délèguent à des éléments indigènes des parcelles de pouvoir et d'autorité alors que justement ces mêmes missionnaires ont fait l'objet d'une sélection particulière en vue d'affronter l'évangélisation des contrées lointaines? On le voit, l'idée compromet non pas les missions mais la façon dont le recrutement des missionnaires, avec ses hiérarchies, a été pensé.

La proposition de 1577 semble être l'aboutissement d'une vingtaine d'années d'échanges divers, lors desquels Rome et les contrées de mission jouent tour à tour le rôle de frein et de moteur. Autrement dit, si le clergé indigène n'a pas été pensé $d^{\prime}$ ' en haut", une même idée sous-tend sur le terrain, les différents cas de figure : la création d'un vivier dans lequel seront prises les nouvelles recrues. Ceci va de pair avec une prise de conscience de la Compagnie : elle ne pourra jamais envoyer aux Indes suffisamment de desservants venant d'Europe. Il faut donc «que la Compagnie puisse croître et durer en ces lieux sans qu'il soit nécessaire d'envoyer continuellement des ouvriers d'ici [d'Europe]» (§ 17).

Il nous semble que la création d'un clergé indigène peut se lire selon deux modèles, pas nécessairement exclusifs : un modèle éducatif et un modèle politique. Dans le premier il s'agit de créer des structures éducatives desquelles émergeront les plus "aptes"; dans le second, l'intention est de créer des structures de vie et d'encadrement des populations indiennes au

${ }^{86}$ Actes de la C.P. du Mexique, 1577 (MM, I, p. 287-343). 
sein desquelles, après complément d'instruction, se dégageront certains individus "civilisés".

C'est en Inde, et somme toute de manière assez improvisée, que se créent des structures éducatives accueillant des fils d'Indiens. Dans les collèges de $\mathrm{Coulao}^{87}$, Cochin, Goa ${ }^{88}$, les élèves sont des fils de notables de la région que l'on instruit et que l'on évangélise et, explicitement dans le cas de Cochin $^{89}$, sans séparer les enfants des Portugais de ceux des Indiens. Ces enfants jouent le rôle de vecteur - on serait tenté de dire : de virus - dans le processus d'évangélisation auprès des populations adultes : ils sont là, dit Polanco, afin de jouer le rôle d' "appât " ${ }^{\circ}$. Au Mexique, et beaucoup plus tard en Nouvelle-France, nous retrouvons la même analogie entre le néophyte (littéralement : la jeune plante) et l'enfant ainsi que le même rôle joué envers les adultes.

En 1555, dans une lettre du même Polanco au provincial du Portugal Miguel de Torres, l'utilité potentielle des collèges est affirmée sans ambiguïté :

Parmi les enfants du collège de Goa, les plus ingénieux et les plus solides dans la foi [...] pourront être admis dans la Compagnie et, bien qu'ils soient accueillis avec davantage de probation que les chrétiens, pour être sortis de l'infidélité, ils ne devront pas l'être avec moins de volonté, s'ils sortent bons ${ }^{91}$.

Dans cette phrase, un peu alambiquée, il apparaît que certains élèves sont des natifs parmi lesquels certains ont pu recevoir une première instruction dans des petites écoles. Deux textes, le premier en 1555 et le second en 1567, nous permettent de faire la jonction entre deux niveaux d'enseignement et laissent apparaître un cycle complet qui associe petites écoles et collèges. Le premier ${ }^{92}$ mentionne l'existence à Goa de petites écoles où l'on apprend, en plus de la doctrine, à lire et à écrire : le texte ne

${ }^{87}$ «Demandes des jésuites au roi du Portugal et réponses du roi, 1549» (Selectae Indiarum epistolae, éd. L. Delplace, Rome, 1887, p. 200). Au collège de Coulao, vivent 3 jésuites et 50 jeunes gens de la région, "fils des notables de la [côte] de la Pêcherie».

${ }^{88} P C$, III, $n^{\circ} 678$. Le collège comprend plus de quarante orphelins et une trentaine d'étudiants externes, "fils des gens hauts placés de cette ville".

${ }^{89} P C$, III, $n^{\circ} 478$. Au collège de Cochin, «150 enfants en partie de Portugais, et en partie d'Indiens » apprennent à lire et à écrire.

${ }^{90} P C$, III, n' 478 : "C'était comme un appât pour éveiller en eux le désir d'apprendre la doctrine et les mœurs chrétiennes [...] ils enseignaient chez eux [...] ils poussaient même leurs parents à se confesser».

${ }^{91}$ Lettre de Polanco à Miguel Torres, provincial de l'Inde, 1555 (S. Ignatii de Loyola epistolae et instructiones. X. 1555-1556, Rome, 1968 [MHSI, 39], p. 175).

${ }_{92}$ Ibid., p. 174. Le texte évoque immédiatement après (p. 176), par une curieuse association d'idées, le corps de François Xavier. 
précise pas leur fréquentation. Ces petites écoles n'appartiennent pas aux collèges mais semblent être dans le même périmètre. Dans le second, la forme même sous laquelle sont exprimées les instructions ${ }^{93}$, rapproche la question des petites écoles de celle du clergé indigène. En effet, les deux paragraphes se suivent :

Voir comment un maître peut s'occuper de ces centaines d'élèves et leur apprendre à lire, écrire et compter [...]

Voir s'il y aurait quelques uns de ces nations, dignes d'être admis dans la Compagnie, ayant fait leurs preuves et étant connus depuis longtemps, ou au moins faire en sorte de les rendre capables d'être des ouvriers pouvant aider l'évêque ou la Compagnie dans la vigne du Seigneur.

Le modèle qui, en Inde, associe petites écoles et choix des plus aptes va tendre à se pérenniser. En 1560, Laínez déclare qu'il lui paraît sévère de fermer la porte aux natifs et ceci, contre l'opinion de François Xavier, reprise par le provincial de l'Inde, selon laquelle les «gens de ce pays ne sont pas aptes pour entrer dans la Compagnie " ${ }^{94}$. Il est nécessaire selon lui d'y regarder au cas par cas. Le parcours de Pedro Luis, Indien converti, est à ce titre exemplaire : élevé dans le collège de Goa, il a aidé à l'évangélisation des indigènes. Puis il a suivi les cours de réthorique et de grammaire et a demandé en 1554 à être admis dans la Compagnie ${ }^{95}$. Il est clair que son "aptitude» plonge en partie ses racines dans une justification sociale : Pedro Luis, en tant que fils de brahmane, est sans doute à la meilleure place pour faire partie de la Compagnie.

Le texte de 1558 prend donc sens à la lumière des expériences sur le terrain : il arrive à un moment où, sans que la question soit pensée de façon globale pour l'ensemble des aires de mission, les généraux de l'ordre doivent donner des réponses précises à des cas spécifiques et des instructions aux supérieurs des provinces. Il apparaît qu'ils doivent envisager des solutions, parfois en émettant un avis contraire à celui des fondateurs de la Compagnie. Enfin, il est clair que le modèle éducatif fonctionne bien dans de "vieilles sociétés» où, selon l'échelle de valeurs des missionnaires, la «civilisation" est chose acquise de longue date. Il suppose également que les enfants des élites indigènes se dirigent assez spontanément vers les struc-

${ }^{93}$ "Instructions de Rome au visiteur des Indes», 1567 (BM, IV, p. 384).

${ }^{94}$ Lettre de Laínez à Antonio de Quadros, provincial de l'Inde, 1560 (BM, III, p. $357-358)$.

${ }^{95}$ Lettre de Laínez à Antonio de Quadros, provincial de l'Inde, 1560 (ibid., p. 358); voir également $P C^{\prime}, I^{\prime I}, n^{\prime \prime} 3380$ et lettre de Pedro Luis à Ignace de Loyola, en 1554, Selectae Indiarum epistolae cit., p. 193-195. 
tures d'enseignement et, bien sûr, que l'instruction soit un signe de distinction sociale ${ }^{96}$.

En ce milieu de XVI' siècle où l'approche des mondes nouveaux suscite l'élaboration de multiples projets d'encadrement des Indiens et des métis, le modèle politique s'impose dans le milieu américain. La première expérience de collège au Brésil est un échec : en 1551, le P. Léonard Nunez pose les premiers jalons d'un établissement scolaire, près de Saint-Vincent, qui comptera en 1554 environ 80 enfants, métis et brésiliens. En 1554, est fondée une nouvelle maison dans un village indien, Pyratininga, qui accueille essentiellement des élèves indiens et reprend quelques élèves de SaintVincent. Bien que cette dernière expérience n'ait pas été un succès, s'ébauche dès ce moment l'idée d'une structure accueillant les élèves et les parents de certains d'entre eux dans une grande maison qui fait figure de micro-société chrétienne ${ }^{97}$.

Cette idée réapparaît quelques années plus tard, en 1562 : le projet des jésuites ${ }^{98}$ consiste à créer des maisons de jeunes gens, fils "d'infidèles" ou de métis, à condition qu'ils aient économiquement de quoi vivre. Sous la direction spirituelle des jésuites et administrés par un laïc, ces derniers apprendraient la doctrine et des mours policées. Parallèlement, dans des maisons de jeunes filles, seraient formées des femmes chrétiennes aptes au mariage avec les garçons issus des établissements symétriques. Le projet est bien celui d'une petite société chrétienne, dans le contexte plus général d'une colonisation appelée à durer; il est complété par la possibilité d'envoyer quelques-uns des garçons au Portugal pour se parfaire «en vertus et en lettres». Ceux d'entre eux qui s'y montreraient aptes pourraient entrer dans la Compagnie; dans le cas contraire, précise le projet, ils deviendraient au moins des interprètes.

L'idée n'est pas nouvelle : une génération plus tôt, en 1531, Don Vasco de Quiroga, «oidor» de l'Audience de Nouvelle-Espagne, soumettait un projet d' "hôpitaux-villages indiens» au Conseil des Indes ${ }^{99}$. Les Indiens, comparés à des "plantes nouvelles et tendres», devraient être regroupés dans des villages (pueblos) et encadrés par quelques frères. Ces derniers veilleraient à ce qu'ils ne perdent pas leur simplicité, car c'est justement

${ }^{96} \mathrm{Au}$ XVII ${ }^{\mathrm{e}}$ siècle, lors des tentatives d'évangélisation de la Chine, les débats autour de la formation d'un clergé indigène prennent en partie sens comme un ultime avatar de ces problématiques : voir sur le sujet F. Bontinck, La lutte autour de la liturgie chinoise aux XVII et XVIII' siècles, Paris-Louvain, 1962.

${ }^{97}$ Voir S. Leite, História da Companhia de Jesus cit., I, p. 254 et PC, VI, no 3280.

${ }^{98}$ Lettre de Laínez à Nobrega, provincial du Brésil, 16 déc. 1562 (LM, p. 577579).

${ }_{99}^{9}$ S. Zavala, Recuerdo de Vasco de Quiroga, Mexico, 1987, p. 11-34. 
cette dernière, ainsi que leur bonté, qui pourront faire d'eux de bons chrétiens. Ces Indiens, selon Quiroga, sont tendres et malléables "comme de la cire", si bien qu'on peut leur imprimer toutes les formes de la civilité. On le voit, la notion de clergé indigène, en Amérique, ne peut se comprendre sans intégrer pleinement la dimension du projet politique.

Deux modèles sous-tendent donc la création d'un clergé indigène. Le premier, proche du système européen de représentation de la société, et notamment des rapports entre clercs et laïcs, met en avant la légitimité des élites et des élites instruites pour servir la Compagnie. Il a visiblement été encouragé par Rome, comme en témoigne le rôle joué par Laínez contre les préventions des "locaux» aussi bien en Inde que plus tard, au Brésil ${ }^{100}$. Le second, produit localement en référence à des modèles utopiques, pourtant préalablement conçus en Europe, rencontre davantage de résistances de la part de Rome. Les documents des années 1550 font apparaître combien le texte de 1558 correspond à une période charnière : de nombreuses expériences existent sur le terrain sans qu'aucune ne donne entièrement satisfaction. Alors qu'émerge un second modèle politique en Afrique - une conversion par les élites et par les réseaux de clientèles qui évacue le problème d'un éventuel clergé indigène - l'essentiel, pour Rome, reste à décider.

En 1577, la proposition de la congrégation provinciale du Mexique vient cette fois des hommes de terrain ${ }^{101}$. Aboutissement d'un processus, les jésuites du Mexique lient de manière intime l'instruction des enfants, l'éducation de chrétiens accomplis et le choix des plus «aptes». Le projet passe par la création de lieux habités uniquement par les Indiens et par la fondation de collèges de la Compagnie destinés aux fils de caciques. Les plus capables de perfection" deviendraient des «dignes ministres de leur nation» car, précisent les pères de la congrégation, "un seul des leurs ferait plus que cent des nôtres", affirmant ainsi l'efficacité de la parole indienne. Ceux qui ne seraient pas aptes à la prêtrise pourraient être formés à des tâches utiles à leur nation et notamment devenir médecins. Comme au Brésil, l'intention est de former un noyau de société chrétienne mais - le terme «nation" est fort - il doit mener à la création d'un corps de jésuites indiens. Cette proposition, intimement liée au contexte de la mise en place, dans les années 1560, de deux "républiques», celle des Indiens et celle des Espagnols, se heurtera à l'attitude embarrassée de Rome. Cette dernière de-

${ }^{100} P C$, III, $\mathrm{n}^{\circ} 3278$.

${ }^{101}$ Actes de la C.P. du Mexique, 1577, MM, I, p. 318. Jean-Paul Zuñiga a élaboré la dernière partie de ces développements sur le clergé indigène, à partir, entre autres sources, des C.P. du Pérou en 1576 et du Mexique en 1577. 
mandera de ne pas innover dans ce domaine et de se contenter d'évangéliser.

Si l'idée d'un corps de jésuites composé de nouveaux convertis se fraie lentement un chemin, avec la mise en place d'un modèle qui prend l'enfant tout jeune, le façonne et en fait un chrétien, un jésuite dans le meilleur des cas, elle se heurte à l'opposition décidée de la plupart des jésuites sur le terrain. Les Mexicains constituent une «anomalie» à un moment où Rome, pragmatique, a déjà opté pour l'avis le plus communément exprimé par les missionnaires. Cependant, les raisons invoquées par ces derniers pour refuser aux indigènes l'accès à la Compagnie méritent attention. Rarement l'argument invoqué est celui de la personnalité même des nouveaux convertis mais davantage l'influence du milieu. Le caractère vicié, délétère des sociétés coloniales, où les occasions de se perdre sont multiples, justifie bien davantage le refus. À cet égard, le vocabulaire employé pour traiter de l'admission des nouveaux convertis («aptitude», "preuves sur le long terme») est le même que celui utilisé lorsqu'il est question de l'admission des Européens nés sur place (les incolas du texte de 1558). La congrégation péruvienne de 1576, qui n'évoque même pas l'idée de former des Indiens à la prêtrise, émet ainsi ses plus grandes réserves quant à l'aptitude des Espagnols nés sur place, en raison de leur inconstance, de leur peu d'inclination à l'étude et de leur éducation dans une société très "libre». C'est l'argument locatif, et non l'argument ontologique, qui sert à refuser l'entrée de certains groupes dans la Compagnie (P. G.).

\section{Mission et clergé séculier}

L'allusion très laconique aux rapports des missionnaires à la papauté dans le document de 1558 : "Considérer quelles aides spirituelles le Siège apostolique peut envoyer dans ces régions, c'est-à-dire les pouvoirs d'absolution, de dispenses et d'indulgences, et tous autres instruments, etc"., semble définir d'emblée la nature des relations avec le clergé séculier pour le demi - siècle que couvre notre documentation (1549-1599). Le SaintSiège apparaît, dans l'esprit du texte de 1558, comme le pourvoyeur de pouvoirs d'absolution, de dispenses et d'indulgences. Tous ces privilèges tendent à faire du jésuite un «clerc singulier» qui échappe quasi totalement à l'emprise de la hiérarchie ecclésiastique normale et concurrence l'activité évangélisatrice de tous. On peut dire que les privilèges dont jouissent les missionnaires les mettent dans un rapport de liberté d'action inversement proportionnel au poids des structures coloniales.

En terre peuplée d'infidèles les jésuites jouissent de toutes les attributions du prêtre, ils peuvent baptiser, marier, et administrer tous les sacre- 
ments aux nouveaux convertis ${ }^{102}$. Ils jouissent de tous les cas réservés aux évêques ou au Saint-Siège ${ }^{103}$, et peuvent même, le cas échéant, de par leur autorité de prêtres, administrer la justice en l'absence de fonctionnaires royaux : au moment de sa mort, le père Antonio Criminale exerçait son «autorité paternelle» en Inde aussi bien dans les affaires spirituelles (enseignement de la doctrine chrétienne) que temporelles (juge des litiges entre autochtones et entre autochtones et Portugais) ${ }^{104}$.

Les missionnaires sur le terrain tentent continuellement de voir leurs privilèges reconduits ${ }^{105}$ ou augmentés en vertu de "circonstances particulières". C'est le danger imminent de mort qui pousse en 1556 les jésuites à demander le privilège d'accorder des indulgences plénières lors du passage du cap de Bonne Espérance par les bateaux portugais ${ }^{106}$. Mais les raisons invoquées peuvent être bien moins dramatiques et relever tout simplement d'une sorte d' "économie de la mission", comme lorsque les missionnaires du Mexique demandent de jouir du droit de jubilé dans toutes les régions visitées afin de permettre une plus "grande moisson" de confessions ${ }^{107}$; raisons proches de celles invoquées par la province du Pérou en 1588, demandant des possibilités élargies d'absolution pour ses missionnaires ${ }^{108}$.

En revanche, dans les territoires qui sont déjà l'objet d'un premier découpage paroissial et qui sont donc encadrés par le clergé séculier, la Compagnie n'a pas pour vocation de se substituer aux séculiers, mais de les seconder. C'est dans ce sens que s'exprime clairement Borgia en 1567 dans ses instructions au visiteur des Indes [du Portugal] ${ }^{109}$, ou la congrégation mexicaine de 1577, qui présente les missions et les visites des jésuites comme le moyen "de ayudar a los clérigos [de los pueblos de Indios] "110.

${ }^{102}$ Lettre du provincial du Pérou, P. Juan de Atienza, au général Claudio Aquaviva, $1^{\mathrm{er}}$ avril 1589 (MP, IV, p. 503). Voir aussi une lettre du 15 novembre 1578 (MP, II, p. 526).

${ }^{103}$ Voir la lettre de Pedro Luis, du collège de Goa, à Ignace de Loyola en 1554 (Selectae Indiarum epistolae cit., p. 195).

${ }^{104}$ Voir la lettre du P. Cipriano sur le martyre du P. Antonio Criminalis, 3 décembre 1549 (ibid., p. 99) et les remarques de B. Vincent, ci-dessous, p. 324-329.

105 Voir, par exemple, les demandes adressées au Saint-Siège par la C.P. péruvienne de 1576, pour obtenir la confirmation du droit d'absoudre de tous les cas réservés à l'évêque ou au pape ( $M P, \mathrm{II}$, doc. 17).

${ }^{106} P C, \mathrm{VI}, \S 3558$, p. 832.

${ }^{107}$ C.P. du Mexique de 1592 (MM, V, p. 182).

${ }^{108}$ Réponses du général Aquaviva, en avril 1591, à un mémorial de la province du Pérou daté de 1588 (MP, IV, p. 782).

109 "Indiarum inspectori instructio", 10 janvier 1567 (BM, IV, doc. 525, p. 383).

${ }^{110}$ Actes de la C.P. du Mexique, 5-15 novembre 1577, (MM, I, p. 320). 
Dans ce contexte, l'activité missionnaire apparaît comme le complément nécessaire à l'activité des curés, le jésuite étant - dans les termes de la congrégation péruvienne de 1576 - une sorte d'“expert» de l'œuvre évangélisatrice"'l.

Les privilèges dont ils jouissent font en effet que les missionnaires sont recherchés comme confesseurs là où les curés ont des pouvoirs limités (notamment pour ce qui concerne les "cas réservés" à l'évêque). La première congrégation péruvienne de $1576^{112}$ souligne ainsi le fait que les Indiens qui font des confessions complètes et sincères sont rares, de peur que le curé soit dans l'incapacité de les absoudre : la confession au jésuite apparaît ainsi comme la confession sûre. C'est pourquoi les missionnaires insistent pour que leurs privilèges soient concédés sans limitation dans le temps et le plus largement possible, comme dans les demandes adressées au SaintSiège par le Pérou en $1576^{113}$ ou plus généralement dans les lettres des provinciaux et celles des congrégations ${ }^{114}$.

À ce caractère complémentaire de l'action du curé, le jésuite joint l'aura qui l'entoure auprès des fidèles indigènes : d'un côté parce qu'il est celui qui absout de tout, de l'autre parce que son activité est gratuite. De par leurs constitutions, les jésuites ne peuvent accepter de charge d'âme et ce principe est souvent rappelé par Rome ${ }^{115}$, bien que les besoins économiques fassent parfois pencher certains missionnaires sur le terrain pour la charge d'âmes, aussi bien au Brésil en 1556 ${ }^{116}$ qu'au Mexique lors des congrégations provinciales de 1577 et de 1592. À chaque fois la réponse de Rome est sans appel : les missionnaires ne doivent rien prendre aux Indiens et vivre des aumônes des Européens habitant à proximité des zones de mission 117 .

Complémentarité avec le clergé séculier, prestige auprès des indigènes sont les deux éléments qui permettent au "prêtre singulier" qu'est le jésuite de remplir le but premier de son ministère : l'évangélisation et l'encadrement des indigènes. Cette finalité première est rappelée aussi

"II Actes de la $1^{\text {re }}$ C. P. du Pérou, 16 janvier 1576 (MP, II, p. 62).

112 Ibid., p. 64.

${ }^{113}$ Ibid., p. 96.

${ }^{114}$ Voir notamment une lettre du P. Juan de Atienza, provincial du Pérou, au général Claudio Acquaviva le $1^{\mathrm{er}}$ avril 1589 (MP, IV, p. 499); la $4^{c}$ C.P., en 1588 (MP, IV, p. 423) et les réponses du général Acquaviva, en avril 1591, aux questions posées en 1588 (MP, IV, p. 783).

${ }^{115}$ Voir notamment Indiarum inspectori instructio, 10 janvier 1567 (BM, IV, doc. 525, p. 382).

${ }^{116} P C, \mathrm{VI}, \mathrm{n}^{\circ} 3282$.

117 Voir notamment les réponses à la C.P. mexicaine de 1577 (MM, I, p. 321). 
bien par les congrégations provinciales ${ }^{118}$ que par le général : Mercurian rappelle aux missionnaires mexicains en 1577, que le but principal de la présence de la Compagnie aux Indes c'est l'aide aux Indiens ${ }^{119}$, leitmotiv asséné régulièrement par Rome ${ }^{120}$. Cette vocation première mène à une situation paradoxale : Rome fait remarquer en 1585 que la fondation de collèges draine beaucoup de missionnaires vers des occupations autres que l'évangélisation des "naturels" et ordonne par conséquent que l'on évite toute nouvelle fondation de collège ${ }^{121}$. Dès 1568 , mais dans un contexte européen, François de Borgia précisait que la Compagnie ne devait accepter que peu de fondations de collèges, malgré toutes les propositions qui lui étaient faites, afin de "mieux assurer ceux qui sont déjà fondés "122. Cette opposition entre l'activité pédagogique et l'évangélisation des Indiens est reprise par la congrégation mexicaine de 1592, mais cette fois pour expliquer le manque d'enseignants dans les collèges, les meilleurs éléments, expliquent les jésuites du Mexique, étant destinés à l'évangélisation des Indiens ${ }^{123}$.

Ce paradoxe n'existe bien sûr qu'en raison de la pénurie de missionnaires. Devant cette question sans véritable solution (les collèges sont le lieu où se forment les futurs évangélisateurs des naturels), les jésuites se voient dans l'obligation de collaborer, cette fois d'égal à égal, avec les autres membres du clergé. Cette collaboration se fait notamment par l'intégration des études jésuites au cursus d'autres ordres ou à l'université, comme le prévoit la congrégation mexicaine de $1577^{124}$ : pour pallier le manque d'enseignants, les étudiants des jésuites se rendront à l'université pour les disciplines non assurées au collège, et les étudiants de l'université suivront l'enseignement des jésuites.

Cette coopération n'entraîne cependant pas la disparition du rôle "exceptionnel» du jésuite en milieu urbain : les privilèges de l'ordre sont nombreux, notamment le droit de prêcher dans les rues et sur les places, de confesser tous les fidèles, d'organiser des petites écoles pour catéchiser et alphabétiser les enfants, comme le rappelle la congrégation mexicaine

${ }^{118}$ Voir par exemple la C.P. de Cuzco, en 1576 (MP, II).

${ }^{119}$ Ibid.

${ }^{120}$ Voir notamment les réponses à la C.P. de Cuzco, datées du 11 décembre 1576 (MP, II, p. 59) ou l'«Instruccion particular para el Padre Gonzalo de Avila, visitador del Peru», avril 1591 (MP, IV, p. 759).

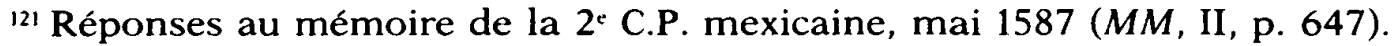

122 «[...] por mejor reforzar los ya hechos", lettre au P. Jerónimo del Portillo, 3 novembre 1568 (BM, IV, p. 653).

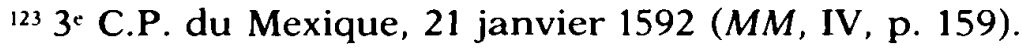

${ }^{124} M M$, I, doc. 112 , p. 339. 
de 1577, et ce, en échappant à la tutelle épiscopale. Cependant, la cohabitation avec un clergé séculier mieux implanté dès lors que la population de souche européenne est plus nombreuse est plus délicat, comme l'attestent les querelles qui opposent régulièrement les jésuites à des évêques qui ne voient pas d'un bon œil ces clercs qui se soustraient à leur autorité : la congrégation péruvienne de 1576 se voit ainsi dans l'obligation de demander le privilège d'excommunier les clercs qui tentent d'entraver leur activité pastorale ${ }^{125}$.

Si la liberté d'action de la Compagnie par rapport au clergé séculier s'amenuise au fur et à mesure que les structures coloniales sont plus implantées, les villes d'Européens, siège des collèges, représentent sans doute le maillon le plus faible de cette chaîne. En milieu européen, le compromis est inévitable et mille tentatives de la société coloniale tentent de réduire les "différences" jésuites (demandes de participation aux fêtes des universités, aux processions... $)^{126}$. En revanche, c'est dans la sphère indigène que l'on trouve le missionnaire jésuite aux pleins pouvoirs, répondant en même temps à la singularité que déterminent les dispenses et à la spécificité de sa mission de conversion.

Les dispenses sont donc pour les jésuites une manière spécifique d'envisager leur activité missionnaire, et participent ainsi à la définition d'un modo nostro dans la pratique de la Compagnie. Elles sont les outils grâce auxquels le missionnaire jésuite devient un expert indispensable à l'activité évangélisatrice du clergé séculier. En même temps, la définition des activités de l'ordre comme prioritairement et essentiellement tournées vers l'évangélisation des indigènes met en évidence l'opposition entre deux pôles. C'est bien sûr la pénurie de personnel qui détermine l'incompatibilité entre le collège et la mission qui ressort de nos documents, mais audelà, celle-ci traduit l'opposition entre le pôle "colonial" et le pôle autochtone de l'activité missionnaire, ou en d'autres termes, entre le projet colonial et le projet évangélique.

On ne peut en effet séparer la stratégie jésuite de démarcation par rapport à l'activité du clergé séculier de celle qui tend à séparer symboliquement la Compagnie de Jésus de l'ensemble de la société coloniale.

125 "Facultatem ex ....... a Santa Sede», ARSI, Congr. 42, fol. 263v.

126 Voir notamment la C.P. du Mexique de 1577 (MM, I, p. 327) : alors que les jésuites sont, sur place, favorables à une participation aux processions de la Fête-Dieu, Rome répond par un non catégorique, et précise que la Compagnie ne doit participer à aucune procession quelle qu'elle soit. Cette position est rappelée au visiteur du Pérou en 1591 ( «Instruccion particular...», avril 1591, texte cité, MP, IV, p. 762). 
La question qui se trouve en filigrane derrière cette quête de dispenses de tout ordre est celle de la définition d'une activité jésuite dégagée de toute inféodation extérieure. Plus que le modo nostro, ce qui particularise les jésuites c'est leur volonté d'appliquer une méthode - partagée avec d'autres ordres missionnaires - dans un cadre où ils sont les seuls artisans de la conversion, libérés de toutes les «scories" coloniales : la construction de la cité de Dieu se fait en éloignant tous les démons qu'il s'agisse du paganisme où de l'influence délétère de la société coloniale. Les dispenses représentent cette liberté d'action pour un projet évangélique de modelage d'une nouvelle humanité, qui n'accepte aucune compromission. Dans le contexte du patronage royal régissant l'Église dans les colonies ibériques, le clergé séculier fait littéralement corps avec l'entreprise coloniale. Se démarquer du clergé séculier, refuser la charge d'âme (alors que les autres ordres missionnaires, notamment les franciscains, l'acceptent) c'est souligner l'originalité du projet jésuite par rapport à cette entreprise.

Car si les méthodes missionnaires sont les mêmes pour les missions intérieures et extérieures, le cadre colonial donne un caractère réalisable à un projet de régénération qui demeure dans le domaine européen un but théorique, un idéal qui se décline le plus souvent de manière individuelle. Le milieu colonial, en revanche, semble ouvrir la porte à la possibilité d'une régénération collective, à la construction d'une société chrétienne dont il revient à la Compagnie d'être le seul maître d'œuvre (J.-P. Z.).

Le désir du martyre: les conditions du martyre «juste» selon le gouvernement de l'ordre

Dans l'économie générale du texte, le $\$ 16$ marque une rupture par rapport aux articles précédents, qui traitaient essentiellement de la gestion des maisons et collèges. Rupture provisoire d'ailleurs, puisque les éléments suivants renouent avec le propos général. La parenthèse, la pause dont la présence est en apparence incongrue, constitue au contraire un temps fort de la réflexion qui traverse tout le document. Nulle part ailleurs ne sont évoquées avec autant de force qu'ici les fins de la Compagnie - le salut des âmes (le "salut des proches», est-il exactement dit) - et ses moyens - le témoignage de la foi. De même le contenu singulier de ces lignes en rehausse la portée. En effet elles sont les seules à faire référence à des situations concrètes, à des experimenta qui ont servi de base durant de longues années à la Compagnie pour penser l'affrontement du danger de mort. 
Qui était Antonio Criminale? Cet Italien né à Parme arriva à Goa en 1545 ou 1546 en compagnie du père Nicolao Lancillotto ${ }^{127}$. Très vite, François Xavier l'envoya comme supérieur des missionnaires dans la zone du Cap Camorin, forte d'une communauté chrétienne assez nombreuse. Criminale y développa une activité considérable pendant plus de trois ans, allant de village en village en dépit d'immenses difficultés. En effet, les conflits étaient nombreux dans la région et Criminale chercha sans cesse à défendre les indigènes et à aider au réglement des querelles privées au sein de leur population. Au cours de l'année 1549, peut-être en février ou en mai, près de Remanancor, un incident opposant selon toute vraisemblance des brahmanes et des Portugais éclata. Bientôt les brahmanes réunirent une foule considérable - sept ou huit mille hommes selon le récit des compagnons de Criminale - et attaquèrent les Portugais, provoquant la mort de quatre ou cinq d'entre eux et en blessant quelques autres. Tous les autres se réfugièrent sur des navires ${ }^{128}$.

Le père Criminale «aurait pu facilement s'en tirer en montant sur ses navires", tels sont les termes du Chronicon de Polanco ${ }^{129}$. Mais il ne voulut pas abandonner les femmes et les enfants indiens qu'il catéchisait avant de les savoir tous en sécurité. Un Indien chrétien, catéchiste de surcroît, fut tué. Criminale s'agenouilla et pria. Alors deux groupes successifs de cavaliers le menacèrent, le molestèrent, un troisième enfin le mit à terre. Criminale était le premier jésuite martyrisé. Très vite les circonstances de sa mort suscitèrent un débat au sein de l'ordre, ce que reflète notre texte.

"Considérer ce qu'il convient de penser de la manière dont le père Criminalis s'est exposé à la mort" s'interroge notre document. La formulation traduit bien la perplexité qui assaille les jésuites à Rome à la lecture d'un tel exemplum. Il est extrêmement intéressant de comparer les deux lettres adressées par les cinq compagnons de Criminale et la version du martyre rapportée par Polanco dans le Chronicon. Ce dernier suit le récit des jésuites du cap Camorin. Comment pourrait-il en être autrement? Mais autant les missionnaires, sous le choc de la perte de leur supérieur, ne manifestent aucune réserve sur sa démarche, autant les lignes de Polanco sont empreintes de distance. Le secrétaire reprend fidèlement les phrases de la missive qui exaltent la foi et le témoignage de Criminale, soulignant par exemple qu' «ils ne voulut pas abandonner dans le grand péril où ils se trouvaient ceux qu'avec tant de soin il avait baptisés et ins-

${ }^{127}$ Selectae Indiarum epistolae, p. 98-101.

${ }^{128}$ Missionarii S.I. Piscariae episcopo Goano, doc. 71, p. 482-489.

${ }^{129} P C$, II, $\mathrm{n}^{\circ} 519$ 
truits dans la doctrine et la vie chrétienne", ou encore : "car quoique occupé des travaux de la vie active, chaque jour, vingt fois, parfois même trente fois, il fléchissait les genoux pour prier». Et il conclut, apparemment sans ambiguïté : "homme infatigable dans son action pour le service des âmes et cependant très adonné à la contemplation, il excellait, ce qui est rare, en l'une et l'autre forme de charité. Sa mort fut jugée d'une telle vie». Le texte de Polanco introduit pourtant implicitement le doute sur l'opportunité du martyre en le présentant comme un choix, entre d'autres possibilités, donc comme une libre décision, non nécessaire, non dictée par la grâce :

Lui-même aurait pu facilement échapper en montant à bord du navire. Mais il resta parmi eux [les Indiens baptisés] faisant peu de cas de sa propre vie [...]. Des cavaliers arrivent et se jettent sur un chrétien [...]. Dès qu'il vit cet homme mort, le père Antoine s'agenouilla et le recommanda ainsi que luimême au Seigneur. Les premiers cavaliers le virent genoux fléchis et les mains levées vers le ciel, attendant la mort [...]. Lui qui brûlait du désir d'être pauvre, il aide [ses ennemis] à le dévêtir, comme s'il ne voulait rien garder de cette misérable vie, pas même en mourant ${ }^{130}$.

Il n'est pas aventureux d'affirmer que la fin de Criminale a hanté Polanco. Il ne fait pas de doute que notre texte de 1558 , soit près de dix ans après la mort de Criminale, est de sa main. Il est aussi fait allusion aux entreprises du Père Melchor Nuñez, qui pratiquait l'exercice de la disputatio avec des bonzes chinois. Or ce missionnaire s'exposait aux réactions violentes des indigènes sans connaître leur langue, donc sans avoir pris les moyens nécessaires à sa démarche. On doit aussi rapprocher le $\S 16 \mathrm{du}$ texte de 1558 et le récit du martyre de Criminale par le Chronicon d'un document que Polanco adressa à François de Borgia, le 20 juillet 1559 ${ }^{131}$. Borgia se trouvait en Espagne, alors ravagée par une épidémie de peste. Le fléau avait, depuis 1557 plus particulièrement, décimé les populations des royaumes de Valence et de Murcie. A Rome avait été reçue une lettre indiquant qu'une vingtaine de jésuites avaient trouvé la mort en raison de leur zèle auprès des malades. Tout en rappelant que chaque membre de la Compagnie devait être prêt à mettre sa vie en péril pour le salut des âmes, Polanco conseilla aux recteurs de veiller à ce que personne ne s'exposât outrageusement : "Quelquefois le service divin perd plus qu'il n'y gagne». Aussi recommande-t-il d'éloigner maîtres et élèves des collèges des lieux contagieux. On se contentera, pour une bonne édification, de maintenir "un ou deux prêtres et un ou deux coadjuteurs", en prenant soin de préser-

130 Ibid.

${ }^{131} B M$, III, doc. 183, p. $529-530$. 
ver les plus faibles physiquement et les plus intellectuellement remarquables.

La lettre de 1559 de Polanco à Borgia a une grande importance, audelà de son contenu, en raison de la probable identité de vue des deux personnages et de leur rôle éminent à la tête de l'ordre durant de longues années. On les vit réagir à une affaire comparable en de nombreux aspects à celle d'Antonio Criminale, survenue en 1566 en Floride. Le roi Philippe II et son entourage pressaient les jésuites d'envoyer des missionnaires en Amérique espagnole, ce qu'ils n'avaient pas encore fait. Une cédule de février 1566 évoquait la nécessité de 24 missionnaires. Borgia, devenu général de la Compagnie, se montrait peu enclin à les donner sans autre condition, parce qu'il craignait qu'une dispersion excessive des missions n'en menaçât l'efficacité ${ }^{132}$. Cependant trois jésuites prirent part en 1566 à l'expédition dirigée par Pedro Menendez de Aviles. Les pères Pedro Martinez et Juan Rogel et le frère Francisco Villareal s'embarquèrent le 28 juin 1566 à San Lucar de Barrameda ${ }^{133}$. Pedro Martinez était le supérieur de la petite équipe. Le navire, une hourque, faisait partie d'une flotte qui allait au NouveauMexique et dont elle se sépara en août. Arrivés sur les côtes de Floride, deux espagnols, six flamands, le greffier de l'embarcation et le père Martinez gagnèrent la côte sur une barque pour trouver de l'eau potable. N'ayant pu retrouver le bateau, ils sillonnèrent la côte plusieurs jours avant d'entrer en contact avec des Indiens qui se montrèrent menaçants. Martinez voulut recueillir tous ses compagnons, mais il fut agressé. Traîné par les Indiens, il se mit à genoux avant de recevoir le coup fatal.

Ici encore, si les jésuites virent dans ce martyre fondateur l'espérance de fruits abondants de la mission, ils ne tardèrent pas à critiquer l'imprudence de Martinez, qui avait quitté le navire sans raison impérative. François Borgia commente sa mort sans détours dans une lettre adressée

${ }^{132}$ Les mobiles de Borgia apparaissent clairement dans une instruction un peu plus tardive (mars 1567) à Jerónimo Ruiz del Portillo, premier provincial du Pérou ( «Il faut aller dans peu d'endroits, pour que ne soient pas dispersé le peu des nôtres qui peuvent être envoyés pour l'instant $[\ldots]$ ". $M P, I$, doc. $21, \S 1$, p. 121) et dans une lettre du 16 mars de la même année au P. Araoz ( «Je souhaite que les nôtres ne se répartissent pas entre de nombreux endroits, mais que nous nous contentions pour le moment de la Floride où nous avons déjà pénétré», $M F$, p. 162). Il faut également noter que le général jésuite "négocie» avec le le roi d'Espagne le nombre des missionnaires offerts, et que cette négociation implique, dans un premier temps au moins, une certaine résistance aux exigences royales - du côté de Rome plus que du côté du gouvernement espagnol de l'ordre, dont l'autonomie était sans doute moins grande.

${ }^{133}$ F. Zubillaga, P. Pedro Martinez (1533-1566), la primera sangre jesuítica en las misiones norteamericanas, dans $A H S I, 7,1938$, p. 30 s. 
au provincial d'Andalousie, Avellaneda. "Nous souhaitons que ceux qui iront aux Indes soient non seulement désireux de mourir mais assez réfléchis pour conserver la vie et l'employer mieux au service de Dieu Notre Seigneur" ${ }^{134}$. Il est vrai que Martinez avait donné de nombreux signes de son caractère impulsif. À en croire le chroniqueur de la province d'Aragon d'où il était issu, il s'était montré très belliqueux avant d'entrer dans la Compagnie : «Il n'y avait pas de défi [à Valence] où il n'était partie prenante comme offensé, offenseur ou pour le moins témoin »135. Ordonné prêtre en 1558, Martinez ne cessa de demander à être envoyé en mission en Chine, sur les terres du Prêtre Jean, en Allemagne, en Amérique enfin et d'insister sur ses motivations. Dès 1560 (son objectif était alors la Chine), il disait à Laínez vouloir «employer ses forces au service divin jusqu'à répandre le sang et la vie». En octobre, il revenait à la charge "non pour chercher le repos mais pour souffrir pour le Christ». En 1564, à propos de l'Allemagne, il confessait "rêver souvent qu'on le martyrisait». Enfin, sur le point de partir à Séville en 1566, il affirmait «aller, avec la grâce de Dieu, offrir sa vie et son sang dans l'entreprise».

Borgia s'était-il penché sur cette correspondance répétitive? ${ }^{136}$ L'exemple du premier martyr de l'Amérique espagnole rejoint celui du premier martyr en Inde. Et il n'est pas surprenant de trouver sous la plume du nouveau général des accents semblables à ceux de Polanco. Non seulement il fait part de son sentiment à Avellaneda, mais le même mois de mars 1557, il met en garde les candidats à la mission en terre hispano-américaine sous la forme d'une instruction adressée au père Portillo ${ }^{137}$. Ce texte est d'une singulière importance parce qu'extrêmement explicite quant à l'attitude à adopter et aux raisons qui doivent la motiver :

Que [les missionnaires] ne mettent pas sottement leur vie en péril au milieu d'indigènes non pacifiés! Si mourir vite pour le service divin serait bon pour eux, cela ne serait pas utile au bien commun à cause de la pénurie d'ouvriers à la vigne du Seigneur et de la difficulté qu'aurait la Compagnie à les remplacer; si bien que les sorties dangereuses ne pourront être faites sans l'assentiment du supérieur; et que celui-ci s'y refuse s'ils ne sont pas réclamés par les gouverneurs, si eux-mêmes n'y participent pas ou ne mandatent pas une personne de qualité à des affaires d'importance.

Ce même mois capital se termine par une audience accordée par Pie V à Borgia et Polanco, qui font au pape le récit du martyre du père Martinez.

${ }^{134} B M$, IV, p. 431 a.

${ }^{135}$ F. Zubillaga, loc. cit., p. 33.

${ }^{136}$ Sur les lettres de demande d'envoi en mission, ou Indipetae, voir ci-dessus note 82 .

${ }^{137} B M$, IV, p. 431. 
De Criminale à Martinez, la question est demeurée vingt ans au cœur des débats internes à la Compagnie et même, comme on vient de le voir, au cœur de la Chrétienté en général. En effet, le christianisme n'a cessé de se poser la question du martyre. L'Église y voit indéniablement un acte de vertu consistant à demeurer ferme dans la vérité contre les assauts de la persécution, mais les condamnations de ceux qui s'y offraient spontanément ont existé dès les premiers siècles. S'appuyant sur diverses références du Nouveau Testament, par exemple sur le récit de la fuite de Pierre abandonnant sa prison, Thomas d'Aquin insiste sur le fait de ne pas fournir aux autres l'occasion d'agir avec injustice ${ }^{138}$. Les jésuites, Polanco et Borgia à leur tête, font leur cette proposition, aussi valable pour les rares ouvriers de la vigne missionnaire que pour les premiers chrétiens menacés de toutes parts. Par leurs avertissements, ils dessinent une voie moyenne, seule susceptible d'assurer à la fois le respect des vœux prononcés, tout particulièrement celui d'obéissance, et le succès de l'entreprise. Prudence, humilité, charité constituent les vertus essentielles du missionnaire qui, en repoussant la tentation du martyre, administre la preuve décisive de leur possession et de leur pratique; elles limitent en même temps les risques d'hémorragie au sein d'un personnel constamment menacé, dans toute la période, par la pénurie d'effectifs (B. V.).

\section{L'INSTITUTION MISSIONNAIRE}

\section{Structures de gouvernement}

Dès son premier paragraphe, le texte de 1558 aborde la question de la tension entre le centre et les périphéries de la Compagnie de Jésus. Il pose le problème du gouvernement des missions, de la nature et des lieux des instances de délibération en vue de la prise de décision :

Considérer s'il convient d'avoir à Rome et au Portugal, ou dans d'autres lieux comme Goa ou Cochin, un conseil désigné d'hommes qui, par leur jugement, leur expérience des choses et leur esprit de charité, vaillent d'être consultés sur les affaires des Indes; ou [s'il convient] que ce soin soit confié, certainement à Rome aux assistants du préposé général, et ailleurs aux conseillers du provincial, afin qu'ils réfléchissent, confèrent entre eux et réfèrent aux supérieurs, sur ce qui peut servir à augmenter et à conserver les nouveaux chrétiens, et sur ce qui pourrait être mis en œuvre pour amener à la foi les Chinois, Brésiliens et autres.

${ }^{138}$ Actes des apôtres XII, 8-12. 
La proposition d'instituer un conseil spécialisé, à Rome ou ailleurs, pour la délibération et la réflexion sur les affaires des Indes n'eut pas de conséquences pratiques après 1558 , puisque nulle trace d'une telle structure dans la documentation de la Compagnie ne permet d'affirmer son existence. Les archives montrent que l'option décentralisée l'a emporté, à savoir des instances de délibération propres à chaque province (le provincial et ses conseillers), en régulière relation épistolaire avec le préposé général et ses assistants. On peut toutefois se demander pourquoi le problème fut alors posé en ces termes et émettre des hypothèses quant aux raisons du choix effectué à partir des questions de 1558.

Le texte lui-même propose deux champs de réflexion : d'une part le problème de la spécificité des décisions liées aux terres de mission et donc de l'existence d'une instance particulière; d'autre part la question de sa localisation, centrale ou excentrée et, dans le premier cas, du lieu central qu'il convenait de retenir.

\section{Un gouvernement spécifique?}

L'idée de confier l'élaboration des grandes orientations de la politique missionnaire à des hommes d'expérience, pleins de jugement et d'esprit de charité semble au premier abord logique. Au moment où la dernière touche est donnée aux Constitutions, la Compagnie fait l'expérience de son expansion, mais aussi de la difficile gestion de sa croissance en lieux, en hommes et en publics. Le texte auquel nous avons affaire constitue, rappelons-le, le premier volet d'un triptyque formulé en fonction des objectifs de la Compagnie et de la nature de la relation de ses publics avec la foi catholique : 1 . la conversion des infidèles; 2 . le retour des hérétiques protestants et autres au sein de l'Église; 3 . le profit spirituel parmi les catholiques.

Parmi ces questions la mission extérieure constitue un problème spécifique, au même titre que les deux autres. Créer une instance particulière de délibération revient à reconnaître la nécessité d'une "adaptation" aux lieux et aux publics. Ainsi, ce premier paragraphe définit clairement la nature des "affaires des Indes" sur lesquelles l'éventuel conseil spécialisé aurait eu à se pencher : les moyens pour conserver les convertis dans la foi, et ceux pour y amener les infidèles. C'est aussi admettre que la mission aux Indes, appelée à croître en volume mais aussi en diversité, peut à terme constituer une trop grosse responsabilité pour de non-spécialistes.

Dans un tel conseil auraient pu siéger un François Xavier, un Nóbrega, un Acosta et bien d'autres "spécialistes», au fait des différents terrains, des 
méthodes déjà mises en œuvre, mais aussi des enjeux et des conséquences que leurs propositions auraient eu pour la Compagnie et pour la foi. Forts de leur expérience, et de leurs connaissances théologiques, ils auraient eu à réfléchir sur la nature même de la mission de la Compagnie aux Indes, aidés par la correspondance issue des provinces lointaines, source constamment renouvelée d'information.

Les Constitutions portent explicitement :

La fin de cette Compagnie n'est pas seulement de s'employer, avec la grâce divine, au salut et à la perfection de l'âme de ses membres mais, avec cette même grâce, de chercher intensément à aider au salut et à la perfection de celle du prochain ${ }^{139}$.

Pour parvenir à cet objectif, la Compagnie se conçoit dans l'étroite unité de ses membres, assurée par la personne du général, dont la fonction est «d'être, pour tous les membres de la Compagnie, la tête de qui descend sur eux tous l'impulsion qui est nécessaire pour la fin que la Compagnie poursuit ${ }^{140}$. En matière de mission, c'est au général d'assurer le lien avec le pape auquel la Compagnie est liée par un vœu d'obéissance ${ }^{141}$.

Par principe, la mission, synonyme de dispersion, qu'elle ait lieu auprès des infidèles, des hérétiques ou des catholiques, est l'affaire de toute la Compagnie, et son gouvernement celle du préposé général. Sur un plan pratique, toute décision sur les missions aux Indes peut avoir des conséquences générales sur la définition de la discipline, des études, des moyens de subsistance, et altérer la cohérence de la Compagnie ${ }^{142}$. En 1558, les jésuites font déjà l'expérience de la dispersion en provinces, et des difficultés qu'elle oppose à cette unité.

Créer une instance de délibération spécifique pour les missions extérieures à l'Europe pouvait avoir deux types de conséquences : d'une part vider de sa substance le gouvernement central lui même, le préposé général, flanqué de ses assistants, perdant alors sa vocation "généraliste"; d'autre part consacrer officiellement une différence de nature entre les provinces d'outre-mer et les autres, au risque d'entamer l'unité recherchée. On peut émettre l'hypothèse que la décision d'exploiter les instances de gouvernement existantes a pu s'imposer pour cette question de principe : le caractère nécessairement "généraliste" du général et des responsables provinciaux, garantie de l'unité des membres. De surcroît, une telle instance

${ }^{139}$ Constitutions [3], dans Ignace de Loyola, Écrits cit., p. 396.

${ }^{140}$ Constitutions [666], ibid., p. 563.

${ }_{141}$ Constitutions [606], ibid., p. 544.

142 L'exemple des langues le montre largement (voir ci-dessus les remarques de C. de Castelnau). 
supplémentaire, au départ destinée à réfléchir et à délibérer, mais à terme un lieu de pouvoir, pouvait s'avérer difficile à contrôler.

Enfin, l'absence d'un tel conseil, et donc la dissolution de la réflexion dans les structures locales, puis leur retour au gouvernement central permettait de profiter de la diversité des expériences et des sensibilités, qu'une instance instituée, par son caractère filtrant, aurait contribué à gommer. On a donc en quelque sorte privilégié la souplesse, tout en respectant le principe d'une instance de délibération générale et par conséquent centrale ${ }^{143}$.

Où localiser le gouvernement des missions : en Europe ou en terre de mission?

Le premier paragraphe pose le problème du centre et des périphéries lorsqu'il aborde le choix du lieu d'implantation de cet éventuel conseil délibératif. L'alternative principale donne le choix entre l'Europe et les terres de mission, entre une structure excentrée ou centralisée. En 1558 les lieux proposés sont Goa ou Cochin, où la Compagnie est déjà installée et dispose d'une certaine stabilité.

Le choix d'un lieu excentré avait l'avantage d'offrir une expérience immédiate des problèmes spécifiques liés aux missions, à travers des situations concrètes et des individus expérimentés. Autant de moyens d'éviter la rigidité d'une structure européenne, non seulement filtrante mais peut-être à terme dénuée de souplesse par son éloignement même. Cependant un conseil siégeant en Inde aurait pris des décisions concernant le Brésil et à long terme les autres régions dans lesquelles la Compagnie devait entrer. En 1558 la centralité de l'Inde est une réalité vécue au quotidien par les missionnaires se rendant au Japon, en Extrême Orient et en Éthiopie. Ils y passent nécessairement et généralement sont issus de la province indienne. Mais cette centralité n'est pas appelée à durer. Le texte de 1558 nous dévoile ici sa dimension descriptive; sa vocation de projection dans l'avenir s'inscrit dans et à partir du constat de ce qui existe. Peut-être est-ce là sa limite et l'une des raisons pour lesquelles il n'est pas sorti des cartons de la Compagnie.

Il est cependant intéressant de noter que l'idée d'un conseil excentré composé de spécialistes a pu frôler l'esprit et la plume du rédacteur romain

${ }^{143}$ Le projet d'une instance spécialisée ne disparaît pas dans les décennies qui suivent, mais il quitte la sphère de la Compagnie pour entrer dans celle de la Papauté. L'auteur supposé du texte qui nous occupe, Polanco, participa, en tant que secrétaire du général François de Borgia, au projet de création par Pie V, entre 1566 et 1572, d'une congrégation permanente de cardinaux, destinée à réfléchir sur la conversion des infidèles. Voir ci-dessus, p. 278. 
de ce texte. La reconnaissance de compétences spécifiques en matière de mission est évidente, mais le choix de la structure généraliste souligne une tension forte entre une politique pensée comme efficace et confiée à des spécialistes et le principe d'un ordre missionnaire jusque dans ses structures de gouvernement (A. M.).

\section{Rome ou Lisbonne?}

Les deux premiers paragraphes du texte de 1558 ramassent en réalité trois sujets de discussion différents. Les deux premiers sont explicites, le troisième beaucoup moins. Il s'agit d'une part, comme l'a exposé Aliocha Maldavsky, de choisir entre un gouvernement des missions européen (à Rome ou à Lisbonne) et un gouvernement local, en terre de mission (l'Inde, conçue alors comme la mission-mère dans l'Empire portugais); d'autre part de choisir de désigner ou non un «commissaire ou visiteur», délégué du gouvernement central en terre de mission, quelle que soit par ailleurs le premier choix. Ces deux fonctions, commissaire et visiteur, ne sont pas encore clairement différenciées en 1558 : elles le deviendront par la suite, puisque le commissaire présentera l'avantage d'un enracinement local permanent, mais l'inconvénient, corrélatif, d'une marge d'autonomie forte par rapport au gouvernement central, le visiteur l'avantage et l'inconvénient inverse. Mais le troisième sujet de discussion intervient en ce point : car, contrairement à ce que semble indiquer la lettre du texte, le choix de Rome ou de Lisbonne n'est pas un choix indifférent, en particulier parce que le choix d'un commissaire est considéré (et demandé) à cette époque, comme le choix d'un représentant permanent du gouvernement romain à Lisbonne : mais cet aspect de la délibération reste souterrain, bien que l'éditeur Pedro Leturia, trahisse en quelque sorte la communication des deux étages problématiques du texte - l'emplacement d'un gouvernement et la désignation d'un délégué - en plaçant en note du $\$ 1$ la référence d'une lettre, adressée de Lisbonne au général Laínez le 2 novembre 1558 par le futur "visiteur ou commissaire» Inacio de Azevedo, beaucoup plus directement liée au $\S 2$. Qu'on en juge :

S'il vous semblait bon, pour les choix qu'il y a à faire là-bas, ou en raison du plus grand nombre d'informations que nous avons ici des choses des Indes, que l'un de ceux qui résident ici, le P. Dr. Torres ou le P. Luis Gonzalez. [de Camara] par exemple, reçoive la charge de commissaire de ces régions, je crois que cela serait également profitable à ceux qui sont là-bas, étant donné qu'ils dépendent le plus immédiatement de ceux qui sont ici et qui savant précisément ce qu'ils font là-bas ${ }^{144}$.

${ }^{144} L M$, III, p. 613-614. 
On peut établir facilement le lien entre cette lettre, et le refus du gouvernement romain de la Compagnie d'accéder à cette demande ${ }^{145}$ et, sur l'autre versant des deux paragraphes qui nous occupent, une remarque ironique du même Laínez dans une lettre adressée à Manuel da Nobrega, au Brésil, en 1562, à propos de l'envoi «d'un visiteur ou commissaire, comme vous dîtes" ${ }^{146}$. La position globale - et cohérente - du gouvernement de l'ordre apparaît clairement, dans le rapport de ces trois problèmes spécifiques, comme une tentative d'éviter, à l'intérieur, la constitution de pouvoirs locaux forts, et, à l'extérieur, l'association de ces pouvoirs locaux avec les autorités portugaises. Les choix centralisateurs qui en découlent doivent ainsi être interprétés sous l'angle institutionnel et sous l'angle politique. Mais c'est parallèlement, et presque inversement, sous l'éclairage des conséquences très lourdes de ces choix que l'on peut prendre la mesure de l'attention extrême apportée par les Constitutions de l'ordre en général, mais aussi, en particulier, par les délibérations de la première congrégation générale, quelques mois seulement après le rédaction de notre texte, à la composition et au mode de désignation de l'«équipe dirigeante», et tout spécialement des assistants du général, en charge, à Rome, de la «surveillance" du premier responsable et de la supervision des provinces de l'ordre. De la même manière que deux fonctions distinctes de commissaire et de visiteur coexistent finalement dans le gouvernement des missions, les quatre assistants du général élus par la congrégation générale de l'ordre (selon les Constitutions [779]) sont doublés par quatre autres assistants désignés par le général (selon les Constitutions [803]), et spécialement chargés de la supervision des Provinces ${ }^{147}$. Mais les Constitutions précisent aussi que "ces assistants pourront être les mêmes que ceux dont il a été parlé plus haut». Le gouvernement des missions appartiendra alors à des hommes élus et nommés, représentants de la Compagnie (à l'image du commissaire tel que le conçoit Azevedo dans la lettre à Laínez citée plus haut) et représentants du général (à lìmage du visiteur tel que les autorités romaines de l'ordre en concevaient le rôle).

145 On lui préfèrera, quelques années plus tard, la fonction de procureur des missions, "bi-localisée» à Rome et à Lisbonne, et que remplira le même Inacio de Azevedo (voir ci-dessus p. 292-293).

${ }^{146} L M$, VI, p. 577.

147 On notera d'ailleurs que, dans l'énoncé des diverses Provinces, le texte des Constitutions distingue le Portugal et l'Espagne d'une part, et les Indes d'autre part, traçant une ligne de démarcation nette entre les métropoles et leurs colonies. 
Le problème du gouvernement des missions nous reconduit donc, par une voie directe, à celui du gouvernement de la Compagnie en général et aux décisions les plus fondamentales, sur ce terrain, de la première congrégation générale de l'ordre en 1558 et des Constitutions qu'elles adoptent : c'est en quelque sorte une preuve supplémentaire de l'«institution missionnaire», à ce paradoxe près que l'identité de l'institution comme tel et de l'institution missionnaire est à l'œuvre dans l'élaboration des structures du gouvernement central romain, source de l'autorité et gardien de sa circulation (P. A. F.).

\section{La circulation de l'autorité}

Le rôle de la correspondance dans la délégation de l'autorité

Détailler la correspondance reviendrait à faire la liste des documents d'archives disponibles dans le fonds romain. Mais il faut souligner l'insistance des lettres elles-mêmes sur la nécessaire fréquence de cette correspondance, sur l'exactitude et la précision des informations à transmettre depuis les provinces, et sur la typologie qui selon Rome doit organiser ces informations. De la périphérie vers le centre, cette correspondance est faite de documents administratifs précis, qui doivent permettre à Rome de suivre pas à pas les progrès de la province : documents sur son histoire (collèges, résidences), documents de comptabilité et actes légaux, documents servant à la gestion du personnel. Le général a accès au nom des membres des provinces et peut leur écrire des lettres particulières.

Les lettres annuelles ne sont qu'une mise en forme des faits édifiants accomplis par la province et servent à forger en Europe l'image d'une Compagnie de Jésus conforme à son idéal missionnaire. On peut plus particulièrement se pencher, comme nous l'avons fait à de nombreuses reprises dans le cadre de cette enquête, sur les dossiers qui, à l'occasion des congrégations provinciales, circulent entre les provinces et Rome. Les thèmes et les registres abordés dans les différents éléments de la correspondance permettent de comprendre comment se distribue l'autorité à l'intérieur de chaque province.

Les provinces envoient les Actes de la congrégation ${ }^{148}$, rédigés généralement en latin, sur un ton officiel et très général, qui manifeste leur nature légale. Des documents en langue vulgaire, mémoriaux de la province,

${ }^{148} \mathrm{Ne}$ peuvent participer aux Congrégations provinciales que les profès de quatre vœux de la province. 
du provincial, des supérieurs de collèges, et du procurateur complètent le dossier, et précisent les demandes contenues dans les Actes des congrégations, développant avec maints détails les arguments. Dans son mémorial, le provincial reprend les mêmes sujets mais de façon plus explicite, et aborde des cas particuliers ou des thèmes parfois délicats tels que les expulsions. Son rôle est d'expliciter le texte des congrégations. Dans l'autre sens, le général répond précisément question après question à chacun des documents. Les congrégations reçoivent une réponse légale, conformément à leur registre de départ, et le provincial se voit préciser les réponses aux congrégations lorsque celles-ci sont délicates. Le général l'informe de demandes particulières des membres de sa propre province auxquelles il a pu répondre par ailleurs, et il aborde des sujets parfois non évoqués dans les congrégations. En 1592, Aquaviva envoie également un visiteur dans la province auquel il donne des instructions sur des sujets prioritaires et délicats, et le droit de changer ses décisions en fonction de ce qu'il trouve sur place.

La distribution de l'autorité est fonction du degré de précision de l'information dont chacun dispose. La province est informée des réponses aux congrégations, qui peuvent être très sèches et courtes; le provincial reçoit des détails supplémentaires et sur des sujets plus délicats, qui n'ont pas été abordés de façon générale dans les congrégations mais qui ont surgi à l'occasion d'une affaire particulière. Le visiteur arrive, lui, avec les pleins pouvoirs, et l'avantage d'un droit de regard sur le provincial lui même.

Au Pérou, en 1591, seul le visiteur et le provincial nouvellement nommé sont informés par le général de l'interdiction d'admettre des créoles dans la Compagnie. Moins catégorique que l'autre, le texte destiné à la province insiste sur l'extrême prudence avec laquelle il faut procéder en la matière. Le passage concernant cette affaire a cependant été découpé dans le document original, et retrouvé dans les copies conservées à Rome $^{149}$. Dans les années 1610, pour éviter des querelles entre créoles et péninsulaires et garantir l'égalité entre les membres de la province péruvienne, on a décidé de bannir le mot des bouches comme des textes, présents et passés, sans hésiter à découper les lettres de généraux, dans un vain effort de supprimer la mémoire même de la province ${ }^{150}$. Cet exemple

${ }^{149} M P$, IV, doc. 191, § 4, p. 761 (lettre au visiteur Gonzalo de Avila, avril 1591) et doc. 196, § 2, p. 788, lettre - découpée - au futur provincial Juan Sebastian).

${ }^{150}$ Voir en particulier le Memorial du P. Juan de Vázquez (1616), ARSI, Congr. 55, fol. 96-101, en part. fol. 100. 
montre bien, je crois, les enjeux des recherches sur la correspondance pour l'étude des modalités de circulation de l'autorité dans l'institution et, plus généralement, celle de l'identité d'un ordre dispersé (A. M.).

Faire une règle de ce qui est : «moyen» et "manière»

Comme l'indique le $\S 2$ de notre texte, la correspondance, combinée à la circulation des visiteurs, est un opérateur d'institution. Le visiteur doit "observer la manière (modus) appliquée sur place, ou bien les moyens (mediis) dont les nôtres usent pour la conservation et l'augmentation de la religion chrétienne»: le premier terme renvoie une "application" à son modèle, le second, beaucoup plus largement, des "moyens" à une fin qui n'est pas l'observation des règles de l'Institut, mais la «religion chrétienne», c'est-à-dire une fin par rapport à laquelle le modèle de l'Institut n'est lui-même qu'un moyen. On passe ainsi, entre l'un et l'autre terme, de la référence d'un ordre institué à la référence du principe de son institution, d'un modèle établi à un modèle en formation : c'est par la voie de ce passage que l'on peut comprendre toute la portée de la seconde équivalence proposée par le même $\S 2$, entre l'observation de l'avancement du "plan de notre Institut» et l'adaptation de ses Constitutions : la conformité au plan apparaît ici sous la forme (possible) d'une conformation de la règle aux pratiques. Mais il appartient à l'autorité de l'institution, en particulier au moyen de la correspondance qui prolonge les visites, et plus généralement d'un acte d'écriture (des règles adaptées rédigées et laissées lors de son départ par le visiteur, mais qui pourront elles-mêmes circuler), d'effectuer le passage de la conformation à la conformité, d'instituer ce qui est (P. A. F.).

L'adaptation de l'institution et ses limites introuvables : l'adaptation comme règle de l'institution

Le terme d' "adaptation" est présent, en effet, dès le début du texte de 1558 : il faut "voir ce qui des règles et constitutions pourrait être adapté selon les aptitudes des habitants de ces contrées". Les exemples sont multiples : la prise en charge de cures ou leur refus, la pratique du chant choral, la place des langues locales dans les études, la question de l'argent dans la Compagnie. L'adaptation se conçoit comme un mouvement de l'institution vers le dehors, qui se réalise pleinement dans la mission. On peut donc dire que la mission est adaptation. On peut aussi aller jusqu'à penser que le mot adaptation n'a pas lieu d'être puisque l'adaptabilité est inscrite dans les Constitutions elles-mêmes. La Compagnie, à mesure de 
ses activités dans le monde, et a fortiori de la mission, réalise sa propre identité en s'adaptant.

Mais cela ne va pas sans tensions. Les points que nous avons développés, les fonctionnements que nous avons décrits, montrent combien le problème essentiel réside dans la conservation de l'unité dans la dispersion. De ce point de vue, l'existence même de la mission, comme une des vocations de la Compagnie, la met en péril tout en construisant son identité. Paradoxalement, c'est la mission elle-même, qui, dans sa réalisation, sauve la Compagnie de cette perte (A. M.).

Peut-on faire l'histoire du phénomène missionnaire comme d'une somme d'expériences progressivement constituées en corpus normatif? Ou bien un texte comme celui-ci nous permet-il au contraire de montrer comment sont immédiatement à l'œuvre des prescriptions et des codifications universelles - bien que cette imposition puisse être, d'une part, réthoriquement assouplie dans le discours missionnaire et d'autre part, effectivement malmenée sur le terrain missionnaire? Dans le prolongement de cette première question la définition de la Compagnie de Jésus comme ordre missionnaire fait-elle de son adaptabilité infinie le pivot de sa consistance propre ou au contraire le masque de son hétéronomie perpétuelle?

Pour le dire encore plus brutalement, le phénomène missionnaire a-til et garde-t-il dans toutes ces années une autonomie, voire une distance, voire un rapport réellement conflictuel avec l'ensemble du processsus d'expansion et de conquête européenne? Ou les missionnaires ne sont-ils que les chevaux légers - voire la cinquième roue du char colonial? Ce sont ces questions que, nous semble-t-il, un document comme celui auquel nous nous sommes attachés peut permettre d'affronter, si l'on s'efforce, comme nous avons essayé de le faire, d'entendre constamment le texte à deux niveaux : celui de son statut dans la chronologie de l'histoire missionnaire jésuite et de l'évolution des rapports entre l'entreprise missionnaire et la société coloniale; celui de sa fonction sur la scène européenne de la Contre-Réforme dans les dernières années du pontificat de Paul IV (P. A. F.). 
Abréviations bibliographiques :

$B M$, III = S. Francisci Borgia epistolae et acta, éd. I. Rodriguez, V. Agusti et F. Cervós, III, Madrid, 1894 (MHSI, 35).

$B M$, IV $=S$. Francisci Borgia epistolae et acta, éd. I. Rodriguez, V. Agusti et F. Cervós, IV Madrid, 1894 (MHSI, 38).

DI, I = Documenta indica. I. 1540-1549, éd. J. Wicki, Rome, 1948 (MHSI, 70).

DI, II = Documenta indica. II. 1550-1553, éd. J. Wicki, Rome, 1950 (MHSI, 72).

DI, III = Documenta indica. III. 1553-1557, éd. J. Wicki, Rome, 1954 (MHSI, 74).

DI, IV = Documenta indica. IV. 1557-1560, éd. J. Wicki, Rome, 1956 (MHSI, 78).

$D I, \mathrm{~V}=$ Documenta indica. VI. 1563-1566, éd. J. Wicki, Rome, 1960 (MHSI, 86).

$D I, \mathrm{X}=$ Documenta indica. X. 1575-1577, éd. J. Wicki, Rome, 1968 (MHSI, 98).

$D I, \mathrm{XV}=$ Documenta indica. $X V .1588-1592$, éd. J. Wicki et J. Gomes, Rome, 1981 (MHSI, 123).

EX, I = Epistolae S. Francisci Xaverii aliaque eius scripta. 1. 1535-1548, éd. G. Schurhammer et I. Wicki, 2céd., Rome, 1996 (MHSI, 67).

EX, I = Epistolae S. Francisci Xaverii aliaque eius scripta. II. 1549-1552, éd. G. Schurhammer et I. Wicki, 2e éd., Rome, 1996 (MHSI, 68).

LM, III = Lainii monumenta, III, Rome, 1912 (MHSI, 47).

$L M, \mathrm{~V}=$ Lainii monumenta, V, Rome, 1912 (MHSI, 50).

$L M$, VI = Lainii monumenta, VI, Rome, 1912 (MHSI, 51).

$M B, \mathrm{I}=$ Monumenta Brasiliae. I. 1538-1553, éd. S. Leite, Rome, 1956 (MHSI, 79).

MB, II = Monumenta Brasiliae. II. 155-3-1558, éd. S. Leite, Rome, 1957 (MHSI, 80).

MB, IV = Monumenta Brasiliae. IV. 1563-1568, éd. S. Leite, Rome, 1960 (MHSI, 87).

MF = Monumenta antiquae Fioridae, Rome, 1946 (MHSI, 69).

MHSI = Monumenta historica Societatis Iesu .

MJ, II = Monumenta historica Japoniae. II. Documentos del Jápon. 1547-1557, éd. J. Ruiz de Medina, Rome, 1990 (MHSI, 137).

MM, I = Monumenta mexicana. I. 1570-1580, éd. F. Zubillaga, Rome, 1956 (MHSI, 77).

MM, II = Monumenta mexicana. II. 1580-1585, éd. F. Zubillaga, Rome, 1959 (MHSI, 84).

MM, IV = Monumenta mexicana. IV. 1590-1592, éd. F. Zubillaga, Rome, 1971 (MHSI, 104).

MP, I = Monumenta peruana. I. 1565-1575, éd. A. de Egaña, Rome, 1954 (MHSI, 75).

MP, II = Monumenta peruana. II. 1576-1581, éd. A. de Egaña, Rome, 1958 (MHSI, 82).

MP, IV = Monumenta peruana. IV. 1586-1591, éd. A. de Egaña, Rome, 1966 (MHSI, 95).

MX, I = Monumenta Xaveriana, I, Rome (MHSI, 16).

PC, II = Polanci Chronicon, II, Rome, 1894 (MHSI, 3).

PC, III = Polanci Chronicon, III, Rome, 1897 (MHSI, 5).

PC, VI = Polanci Chronicon, VI, Rome, 1898 (MHSI, 11). 


\section{ANNEXE}

LE DOCUMENT DE $1558^{\prime}$

Rome, février-août 1558 (ARSI, Instit. 18, 431r-434v)

Des questions qui semblent devoir être traitées par notre Compagnie pour la plus grande gloire de Dieu et le bien commun

En premier lieu les questions qui concernent la conversion des infidèles et leur conservation, principalement en Inde, etc.

Ensuite les questions qui concernent la réduction des schismatiques et des hérétiques au sein de l'Église et leur conservation, dans le Nord comme dans le Sud et dans les régions d'Éthiopie.

Après quoi seulement on traitera du profit spirituel fait parmi les catholiques dans les lieux où notre Compagnie est installée.

\section{[De la conversion et de la conservation des infidèles; de l'institution d'un conseil]}

1. Considérer s'il convient d'avoir à Rome et au Portugal, ou en d'autres lieux comme Goa ou Cochin, un conseil désigné d'hommes qui, par leur jugement, leur expérience des choses et leur esprit de charité, vaillent d'être consultés sur les affaires des Indes; ou [s'il convient] que ce soin soit confié, certainement à Rome aux assistants du préposé général, et ailleurs aux conseillers du provincial, afin qu'ils réfléchissent, confèrent entre eux et réfèrent aux supérieurs, sur ce qui peut servir à augmenter et à conserver les nouveaux chrétiens, et sur ce qui pourrait être mis en œuvre pour amener à la foi les Chinois, Brésiliens et autres.

\section{[Si un visiteur doit être envoyé]}

2. Considérer si, en plus de ceux qui vivent dans cette sorte d'endroits, il convient d'envoyer quelqu'un du gouvernement de la Province, qu'il soit commissaire ou visiteur, avec deux objectifs principaux. Il s'agit d'abord d'observer la manière appliquée sur place ou bien les moyens dont les nôtres usent pour la conservation et l'augmentation de la religion chrétienne, afin de les aider et de les diriger si cela est nécessaire. Il s'agit aussi d'observer l'avancement des choses conformément au plan de notre Institut, et, dans la mesure du possible, de voir ce qui des règles et des constitutions pourrait être adapté selon les aptitudes des habitants de ces contrées; tout cela afin que les nôtres se consacrent au secours de ceux qui nous sont proches, en sorte que ces derniers puissent eux-mêmes s'affermir auprès des autres, et mieux même qu'ils s'emploient à leur augmentation en qualité comme en quantité, lorsque leur aptitude naturelle y portera. Si toutes ces conditions sont réunies et que les habitants des Indes peuvent seconder les nôtres, une instruction supplémentaire pourra être envoyée en ces lieux.

' Les italiques signalent un soulignement dans le texte; les crochets, des inscriptions marginales; les soulignements, les ajouts autographes de Juan de Polanco, premier secrétaire de Diego Lainez, général de la Compagnie en 1558; les soufflets $(<>)$ signalent les mots raturés dans le manuscrit. 
[De l'envoi d' “ouvriers" aux Indes]

3. Considérer si de nouveaux ouvriers doivent être envoyés dans les contrées précédemment évoquées, ou bien même dans les autres, si elles sont jugées propres à la moisson, en veillant à cette fin à ce que l'on se soit assuré qu'ils aient été appelés intérieurement pour une mission de ce genre et que l'on ait estimé qu'ils avaient la capacité d'accomplir cette tâche. Que parmi eux une sélection soit faite : doivent être choisis ceux qui pourront être envoyés sans préjudice grave pour les régions proches et pour le profit des régions lointaines; et s'il se trouvait qu'il en restait encore beaucoup parmi les coadjuteurs en formation ou les élèves, on choisira ceux qui ont été dotés d'un talent moindre dans les lettres, mais de grandes vertus morales. Là-bas, en effet, ces vertus peuvent être extrêmement utiles, alors qu'elles ne le sont ici que médiocrement.

\section{[Aide du Siège apostolique]}

4. Considérer quelles aides spirituelles le Siège apostolique peut envoyer dans ces régions, c'est-à-dire les pouvoirs d'absolution, de dispenses et d'indulgences, et tous autres instruments, etc.

\section{[Faveur des princes]}

5. Examiner quelles faveurs les princes séculiers peuvent procurer [aux missionnaires], en sorte que les néophytes soient traités avec humanité, encouragés et aidés de toutes parts, et que la dîme ne pèse pas sur eux plus que sur les vieux chrétiens.

\section{[Érection des maisons et des collèges]}

6. Considérer si les collèges, les maisons et les églises doivent nous être confiées ou être construites depuis leurs fondements, comme c'est le cas de la maison professe de Goa.

Considérer s'il faut construire dans l'île voisine de Choran une maison pour la santé des nôtres, pour le profit spirituel des nouveaux chrétiens ou pour ceux qu'il reste encore à amener au Christ.

Considérer s'il faut constituer dans la ville de Cochin une maison professe, ou un collège seulement, ou les deux.

Considérer ce à quoi il faut veiller pour l'église Sainte Marie, que les nôtres utilisent, soit réellement achevée.

Considérer s'il faut que nous soit confié un collège à Canganor, ou si nous devons nous-mêmes le fournir, et si doit nous être confié une maison ou un collège à Chaul.

Considérer s'il convient de choisir d'autres lieux, dans la région dont Comorin est capitale, pour que les nôtres y résident, ou si la plupart des nôtres ne doivent pas résider dans leurs propres maisons, afin de conserver dans la religion chrétienne tout ce peuple. Considérer de même, au Brésil, qui devrait résider dans certains lieux, et qui dans nos maisons ou nos collèges, et, dans ce dernier cas, si cela devrait être pour un certain temps ou continûment.

Considérer ce qui doit être fait pour le collège de Caulam, afin qu'il ne doive pas être détruit un jour malgré le voisinage de la forteresse. 


\section{[Penser à la manière d'amener les infidèles au Christ]}

7. Imaginer la manière dont il faut user pour attirer les Brésiliens à la foi et pour les y maintenir.

Parmi les Chinois et les habitants des côtes d'Afrique, on veillera à aider ceux qui sont disposés à la foi.

Pour ce qui est de l'Inde soumise au roi Philippe, réfléchir sérieusement s'il faut passer par les paraguayens ou par une autre voie, et s'il convient d'attendre une occasion ou de la rechercher.

\section{[De l'évêque du Japon]}

8. Considérer s'il faut nommer un évêque à la tête des japonais, afin que certains puissent recevoir les ordres sacrés, et comment, dans ce cas, négocier cette affaire.

\section{[Des collèges proches des Sarrasins]}

9. Pour ce qui est des collèges de Constantinople, de Jérusalem, de Chypre et de Raguse, considérer s'il faut tenter quelque chose avec les sarrasins, et, puisque les nôtres traversent avec l'armée en direction d'Oran, s'il faut résider quelque part en Afrique du Nord, afin qu'au moins par l'exemple et si quelque chose leur est permis ils puissent être utiles aux sarrasins; ou, en attendant conserver et faire progresser les chrétiens.

\section{[Des enfants que l'on garde dans les maisons]}

10. Considérer si, dans les lieux très éloignés, les nôtres peuvent garder dans leurs maisons les enfants qu'ils y accueillent pour les instruire, comme c'est le cas à Goa et ailleurs, et si cela convient tout à fait qu'il doive exister un réfectoire différent et des chambres séparées pour les nôtres et pour eux, et décider comment nos constitutions doivent être observées dans ce genre de lieux sur ce sujet.

\section{[De la propriété des esclaves et des troupeaux]}

11. Considérer s'il doit être permis que dans certains endroits les maisons possèdent des domestiques et des esclaves non religieux, et s'il est possible de posséder des troupeaux pour l'entretien de ces esclaves et de ces serviteurs; et, dans ce type d'affaires, de donner aux provinciaux la faculté d'accorder des dispenses par rapport aux constitutions et aux règles et d'adapter ces règles aux lieux et aux personnes, pourvu qu'on avertisse le général des règles que l'on n'observe pas et pour quelle raison on ne les observe pas.

\section{[Du provincial ou du commissaire japonais]}

12. Considérer s'il convient de mettre à la tête des japonais un provincial différent du provincial de l'Inde, ou s'il faut un commissaire qui dépende du provincial de l'Inde et qui dirige tous ceux des nôtres qui sont dans cette région, alors que les échanges sont difficiles et rares; et s'il convient de recourir à une seule personne pour les lieux variés de cette province, [soit Malacca, Amboine et les îles Mauri]. 
[Du chant etc.]

13. Considérer si l'on doit permettre le chant en Inde et dans tous autres lieux très éloignés, bien qu'en Europe la Compagnie ne les autorise pas, si par lui ces nations sont orientées vers le culte de Dieu et aidées au profit spirituel, comme on l'observe à Goa et en Éthiopie.

\section{[De la gestion des hôpitaux]}

14. Considérer si l'on doit permettre dans ces régions d'assumer la charge de gérer les hôpitaux, comme à Goa, Punincalli et Bungo, les gens du dehors n'étant pas de confiance, afin de faire de meilleures preuves et d'être d'une plus grande édification envers ces mêmes gens; si leur conduite le permet, qu'on leur confie ce soin. Mais si nul n'est fiable, que l'on puisse assumer nous-mêmes la charge.

\section{[Si les profès peuvent avoir une habitation dans les collèges]}

15. Considérer si l'on déclare que les profès peuvent vivre dans les collèges de ces régions, quand ils ne peuvent pas vivre de la quête des aumônes et selon ce qu'ils jugeront eux-mêmes.

\section{[De l'affrontement du danger de mort]}

16. Considérer s'il convient d'annoncer quelle attitude les nôtres doivent adopter en face d'un danger mortel, quand ils doivent l'affronter ou le fuir, afin le saint désir du martyr ne conduise pas à affronter la mort d'une façon peu discrète et utile, ou pire encore, au détriment de l'obéissance divine qui est souhaitable; ou qu'au contraire une prudence excessive, sous le prétexte du discernement, ne détourne du témoignage que l'on doit rendre de notre foi et de notre religion pour la gloire du Christ, ou de la recherche du salut des proches. Et particulièrement considérer ce qu'il convient de penser de la manière dont le $\mathbf{P}$. Criminalis s'est exposé à la mort et de celle dont le P. Melchior Nunez l'a risquée en ramenant les Chinois à la foi du Christ.

\section{[De l'admission dans la Compagnie des <extérieurs> habitants des Indes <pour l'œuvre de Dieu>]}

17. Considérer si, parmi les habitants de ces régions, certains peuvent être rendus aptes à supporter les Règles de notre Compagnie, soit qu'on les forme à Goa, soit qu'on les envoie au Portugal ou dans d'autre collèges d'Europe, pour qu'ensuite la langue vernaculaire leur soit utile et que la Compagnie puisse croître et durer en ces lieux, sans qu'il soit nécessaire d'envoyer continuellement des ouvriers d'ici; et ceci parce que, si ce n'est dans toutes les régions, du moins dans certaines, quelques-uns semblent pouvoir être choisis, qui soient riches en talent et en disposition par rapport aux autres.

\section{[Comment les nôtres apprennent des langues]}

18. Il faudrait aussi que les nôtres envoyés depuis l'Europe apprennent les langues de cette sorte de nations, et qu'ils soient aidés pour cela par la grammaire et par l'usage, si vraiment on juge qu'ils ont des dispositions pour cela. 


\section{[Des indigènes employés à l'ouvre du Christ]}

19. Considérer si certains des indigènes pourraient être rendus aptes à la conversion et à la conservation des autres, bien qu'ils n'appartiennent pas à la Compagnie, soit en recevant les ordres sacrés soit en demeurant dans l'état laïc, et de quelle manière.

[Comment ceux qui sont à la tête font preuve de bienveillance à l'égard de leurs subordonnés]

20. Puisque, à cause des chrétiens qui provoquent l'inhumanité et le défaut de charité, la conversion des infidèles et le progrès de ceux qui étaient déjà convertis ont été jusqu'ici empêchés, considérer s'il faudrait s'appliquer, grâce à la piété de la reine et à son zèle pour la gloire de Dieu, à ce que le vice-roi se montre bon à l'égard des chrétiens et mette à leur tête d'autres gouvernants humains et pieux; alors les choses du monde iront plus aisément devant l'espérance que la cause du Christ avance sérieusement.

\section{[Des suffrages des prières et des messes]}

21. Pour ceux qui suivent le dessein de la Compagnie toute entière, considérer comment faire avec soin pour qu'ils recommandent à Dieu chaque jour la cause de cette sorte de région, à laquelle nous travaillons nous-mêmes, et pour qu'ils aident par le sacrifice de la messe.

[Tout ceci à traiter en vue des fins de la Compagnie] ${ }^{2}$

${ }^{2}$ Cette dernière ligne est un ajout autographe de Jérôme Nadal, surintendant du Collège romain de la Compagnie en 1558. 